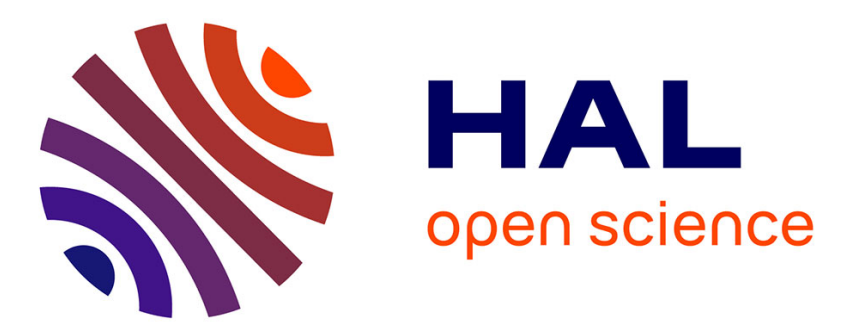

\title{
Acrylic-Alkyd Hybrids: Secondary Nucleation, Particle Morphology, and Limiting Conversions
}

Ravindra Udagama, Carolina de Las Heras Alarcón, Joseph Keddie, John Tsavalas, Elodie Bourgeat-Lami, Timothy Mckenna

\section{- To cite this version:}

Ravindra Udagama, Carolina de Las Heras Alarcón, Joseph Keddie, John Tsavalas, Elodie BourgeatLami, et al.. Acrylic-Alkyd Hybrids: Secondary Nucleation, Particle Morphology, and Limiting Conversions. Macromolecular Reaction Engineering, 2014, 8 (9), pp.622 - 638. 10.1002/mren.201400003 . hal-01859694

\section{HAL Id: hal-01859694 \\ https://hal.science/hal-01859694}

Submitted on 22 Dec 2021

HAL is a multi-disciplinary open access archive for the deposit and dissemination of scientific research documents, whether they are published or not. The documents may come from teaching and research institutions in France or abroad, or from public or private research centers.
L'archive ouverte pluridisciplinaire HAL, est destinée au dépôt et à la diffusion de documents scientifiques de niveau recherche, publiés ou non, émanant des établissements d'enseignement et de recherche français ou étrangers, des laboratoires publics ou privés. 


\title{
Acrylic-Alkyd Hybrids: Secondary Nucleation, Particle Morphology and Limiting Conversions
}

\author{
Ravindra Udagama ${ }^{1}$, Carolina de las Heras Alarcón ${ }^{2}$, Joseph L. Keddie ${ }^{2}$, John G. Tsavalas ${ }^{3}$, \\ Elodie Bourgeat-Lami ${ }^{1}$, Timothy F.L. McKenna ${ }^{1}$ \\ ${ }^{1}$ Université de Lyon, Univ. Lyon 1, CPE Lyon, CNRS UMR 5265, Laboratoire de Chimie, \\ Catalyse, Polymères et Procédés (C2P2), LCPP group, 43 Bd du 11 Novembre 1918, F- \\ 69616, Villeurbanne, France. \\ ${ }^{2}$ Department of Physics, University of Surrey, Guildford, Surrey, GU2 7XH, U.K. \\ ${ }^{3}$ Nanostructured Polymers Research Center, University of New Hampshire, Durham, NH, \\ USA
}

\begin{abstract}
The chemical incorporation of an alkyd with unsaturated double bonds into an acrylic polymer created via miniemulsion polymerisation was studied. The variation of the number ratio of polymer particles $\left(\mathrm{N}_{\mathrm{p}}\right)$ to initial droplets $\left(\mathrm{N}_{\mathrm{d}}\right)$ with monomer conversion and the changes in individual monomer conversions with increasing alkyd concentration were the main data used to study the effect of increasing alkyd quantity in the hybrid system. It was shown that more homogeneously nucleated particles were observed for hybrid systems rich in the more hydrophilic methyl methacrylate (MMA) than is the case when the monomer mixture is rich with the more hydrophobic butyl acrylate (BA). When the hybrid system was composed of MMA and BA in the presence of both saturated and unsaturated alkyd resins, changes in particle morphology with monomer conversion, as well as limited monomer conversion were observed. It is postulated that the better compatibility of BA (as compared to the more hydrophilic MMA) with the particular alkyd resins used in this study is the basis for this result. This emphasises the importance of proper pairing of the miscibility between the specific acrylics and alkyds used in these hybrid polymers, not only the double bond character of the alkyd component.
\end{abstract}

Key words: alkyd, hydrophobe, limiting conversion, latex film formation, hybrid latex 


\section{Introduction}

Alkyd resins are widely employed in paint applications due to their useful properties such as auto-oxidative curing, high gloss and good penetration into wood ${ }^{1}$. However, the synthesis of traditional solvent-borne alkyd resin-based paints has come into disfavour due to the presence of volatile organic species ${ }^{2}$, making it important to find alternative processes, and preferably water-based ones. The major difficulty in doing so lies in the fact that alkyd resins cannot be easily incorporated into environmentally-friendly acrylic latexes by conventional emulsion polymerisation because of the way the polymer particles are formed. In a conventional emulsion polymerisation process, monomer needs to diffuse through the water phase to the particles, and since alkyds are so hydrophobic they will not do so. Alternatively, physical blends of alkyds and acrylic latexes often suffer from incompatibility of the two polymer types resulting in hazy or non-uniform films ${ }^{2,3}$. It appears that an appropriate way to make water-borne, environmentally benign hybrid polymers that synergistically combine the positive properties of alkyd resins with the fast drying and color retention of acrylic latexes is via the polymerisation of a miniemulsion dispersion ${ }^{1-7}$.

In a miniemulsion, nano-sized droplets are formed in water using some type of intense mechanical mixing (e.g. sonication, high pressure homogenisation or static mixers). The nanodroplets are small enough that (in the absence of micelles) they can become the prevalent locus of particle nucleation. This means that if one can directly incorporate a product such as an alkyd resin in the monomer before it is dispersed, it should be possible to create polymerpolymer hybrids in situ by nucleating each one of the initial droplets. Ideally this will yield a 1:1 copy of droplets to particles ${ }^{1-7}$, such that the number of droplets, $N_{\mathrm{d}}$, exactly equals the number of polymer particles, $N_{\mathrm{p}}$.

As with a conventional emulsion, a miniemulsion must be stabilised to prevent coalescence by collision using surfactants, but it must also be formulated to prevent degradation of the particles by molecular diffusion (Ostwald ripening) ${ }^{8-12}$. Typically, hydrophobes are short chain compounds with extremely low water solubility, such as hexadecane or octadecane, however it has also been shown that alkyd resins with unsaturated double bonds can be used as both hydrophobe and grafting agent in acrylate miniemulsion polymerisation ${ }^{5,6}$. In situ grafting of growing free-radicals to the unsaturated alkyd resin increases the compatibility between the two phases and prevents phase separation ${ }^{13-18}$.. Prevention of phase separation in alkyd-acrylic hybrid particles is of major importance in order to promote further homogeneous repartition of the alkyd polymer within the hybrid film ${ }^{19-23,38,39,40}$. Thus one of the keys to producing useful film-forming latex will be to understand the relationship between the morphology of the hybrid particles and the formulation used to make them ${ }^{23}$.

In terms of producing a homogeneous film, the most desirable reaction scenario is one in which all the monomer droplets contain alkyd resin and are polymerised to yield particles such that a one-to-one copy of droplets to particles is obtained. If $\mathrm{N}_{\mathrm{p}} / \mathrm{N}_{\mathrm{d}}$ is different from unity, it is preferable that this ratio be slightly less than one rather than slightly greater than one. In the latter case, this implies that new particles have been created, most likely by stablilisation of homogeneously nucleated particles, during the reaction and these new particles would not contain alkyds. This has not been studied in detail for acrylic-alkyd hybrid latexes, and we will investigate the relationship between the loading of alkyds and the nucleation of new particles during the reaction.

Alkyd-acrylic hybrid systems also suffer from limiting monomer conversion, especially as the alkyd content increases ${ }^{24-29}$. The decrease of the final monomer conversion with increasing 
alkyd quantity has been discussed previously, and two mechanisms have been proposed to explain limiting monomer conversion, one physical and one kinetic, but no clear consensus has been reached on the causes of this phenomenon ${ }^{24,25}$. Some have found that substituting the alkyd for its smaller constituents, namely the seed oil or fatty acids themselves, can help increase the overall conversion, yet the debate on the role of the alkyd itself towards a limiting conversion remains open ${ }^{30}$.

The goal of these hybrids is to have uniform distribution of the alkyd and acrylic phases within each particle, and also to have the two phases sufficiently grafted, so as to prevent phase separation during both particle formation and film formation. Achieving high monomer conversion is equally as important because volatile organic content (VOC) is undesirable from an environmental standpoint and residual unreacted monomer will plasticize the film and can thus enable increased, and undesirable, phase separation.

It is possible that issues that influence the final number of particles, overall conversion and product morphology are related to thermodynamic interaction of the alkyd resins, the monomer and the polymer formed during the reaction. Therefore in this study we focused our attention on the evolution of $\mathrm{N}_{\mathrm{p}} / \mathrm{N}_{\mathrm{d}}$ in the presence of varying amounts of alkyd. We correlated this evolution with droplet stability, and showed that important information on the change of particle morphology could be found if one looks at the change of individual monomer conversion and the evolution of $\mathrm{N}_{\mathrm{p}} / \mathrm{N}_{\mathrm{d}}$ simultaneously.

Herein, we present the details of our experimental study performed on a model acrylic-alkyd system suitable for a waterborne coating. The acrylic part consisted of a mixture of methyl methacrylate (MMA) and butyl acrylate (BA) in equal parts by weight, with $1 \mathrm{wt} \%$ of acrylic acid (AA). The alkyd used was predominantly mono-unsaturated (see supporting information, Figure S5) in the long chain fatty acid groups, but was also compared with a saturated form.

\section{Experimental}

\subsection{Materials}

Butyl acrylate (BA 99+ \%; from Acros; Illkirch Cedex, France), acrylic acid (AA 99+ \%; from Acros; Illkirch Cedex, France) and methyl methacrylate (MMA 99+ \%; from Acros; Illkirch Cedex, France) were used as received. Dowfax-2A1 (45\% graciously supplied by The Dow Chemical Company) was used as the anionic surfactant, and the amount of surfactant mentioned in the recipes always refers to total surfactant weight (active matter + additional water). A long chain unsaturated oil alkyd resin (SETAL 293 XX - 99; 98\% solid and 2\% xylene as the solvent), graciously supplied by Nuplex Resins, was used in most of the experiments. A saturated alkyd resin (98\% solid and 2\% xylene), also supplied by Nuplex Resins, was also used in a few experiments. Hexadecane (99+\%; from Acros; Illkirch Cedex, France) and octadecyl acrylate (ODA 97\%; from Sigma Aldrich; Lyon, France) were used as hydrophobes. Potassium persulphate (KPS Analytical grade; from Acros; Illkirch Cedex, France) was used as the water-soluble initiator. A solution of $37.5(\mathrm{wt} \%)$ of $\mathrm{NaHSO}_{3}(\mathrm{MBS}$; from Sigma Aldrich; Lyon, France) was used with KPS during the semi-continuous addition of KPS, and the amount of $\mathrm{NaHSO}_{3}$ stated in the recipes always refers to total weight (active matter + additional water). The oil-soluble initiators were dilauryl peroxide (Analytical grade; from Acros; Illkirch Cedex, France) and azobisisobutyronitrile (AIBN Analytical grade; from Acros; Illkirch Cedex, France). Tertiary butyl hydroperoxide (TBHP diluted at 70\% in water; from Acros; Illkirch Cedex, France) and sodium formaldehyde sulfoxylate (SFS Analytical grade; from Sigma Aldrich; Lyon, France) were used as the redox initiator pair. 


\subsection{Miniemulsion Preparation and Polymerisation}

All reactions were carried out in a $200 \mathrm{~mL}$ jacketed glass reactor connected to a heated water bath for temperature control. The reactor was equipped with a stirrer, reflux condenser, nitrogen inlet and outlet, and a valve on the bottom to remove the latex.

The initial runs performed to achieve a stable hybrid miniemulsion are provided in Table 1 . Other recipes were also used throughout the course of this work, with different initiator feed strategies, and alkyd levels going up to $50 \mathrm{wt} \%$ with respect to total mass are shown in Table 2 and Table 3 respectively. In order to facilitate the discussion, they will be presented at the pertinent spot during the discussion of results but they are similar to those shown in this table.

Table 1. Experimental conditions for single initiator shot miniemulsions

\begin{tabular}{cccccccccc}
\hline Run & $\begin{array}{c}\mathrm{H}_{2} \mathrm{O} \\
(\mathrm{g})\end{array}$ & $\begin{array}{c}\text { Dowfax } \\
(\mathrm{g})\end{array}$ & $\begin{array}{c}\text { BA } \\
(\mathrm{g})\end{array}$ & $\begin{array}{c}\text { MMA } \\
(\mathrm{g})\end{array}$ & $\begin{array}{c}\text { AA } \\
(\mathrm{g})\end{array}$ & $\begin{array}{c}\text { Alkyd } \\
(\mathrm{g})\end{array}$ & $\begin{array}{c}\text { Alkyd } \\
(\mathrm{wt} \%)^{\mathrm{a}}\end{array}$ & $\begin{array}{c}\text { ODA } \\
(\mathrm{g})\end{array}$ & $\begin{array}{c}\text { KPS } \\
(\mathrm{g})\end{array}$ \\
\hline 1 & 82.5 & 0.25 & 9.9 & 9.9 & 0.2 & 0.12 & 0.6 & - & 0.04 \\
2 & 82.5 & 0.25 & 9.9 & 9.9 & 0.2 & 0.52 & 2.6 & - & 0.08 \\
3 & 82.5 & 0.25 & 9.9 & 9.9 & 0.2 & 0.52 & 2.5 & 1.03 & 0.08 \\
4 & 64.0 & 1.5 & 19.8 & 19.8 & 0.4 & 0 & 0 & 2.0 & 0.16 \\
5 & 64.0 & 1.5 & 19.8 & 19.8 & 0.4 & 2 & 5 & 2.0 & 0.16 \\
6 & 64.0 & 1.5 & 19.8 & 19.8 & 0.4 & 4 & 10 & 2.0 & 0.16 \\
7 & 64.0 & 1.5 & 19.8 & 19.8 & 0.4 & 6 & 15 & 2.0 & 0.16 \\
8 & 64.0 & 1.5 & 19.8 & 19.8 & 0.4 & 10 & 25 & 2.0 & 0.16 \\
\hline
\end{tabular}

${ }^{\mathrm{a}}$ In weight percent based on monomers, SETAL 293 XX

Table 2. Recipes of the miniemulsion polymerisation reactions performed to increase monomer conversion.

\begin{tabular}{|c|c|c|c|c|c|c|c|c|c|c|c|c|}
\hline Run & $\begin{array}{c}\mathrm{H}_{2} \mathrm{O} \\
(\mathrm{g})\end{array}$ & $\begin{array}{l}\text { Dowfax } \\
\quad(\mathrm{g})\end{array}$ & $\begin{array}{l}\text { BA } \\
(\mathrm{g})\end{array}$ & $\begin{array}{l}\text { MMA } \\
(\mathrm{g})\end{array}$ & $\begin{array}{l}\text { AA } \\
(\mathrm{g})\end{array}$ & $\begin{array}{l}\operatorname{Alkyd}^{c} \\
(\mathrm{~g})\end{array}$ & $\begin{array}{c}\text { ODA } \\
(\mathrm{g})\end{array}$ & $\begin{array}{c}\text { KPS } \\
(1) \\
(\mathrm{g})\end{array}$ & $\begin{array}{c}\text { KPS (2) } \\
(\mathrm{g})\end{array}$ & $\begin{array}{c}\mathrm{NaHSO}_{3} \\
(\mathrm{~g})\end{array}$ & $\begin{array}{l}\text { TBHP } \\
(\mathrm{g})\end{array}$ & $\begin{array}{c}\text { SFS } \\
(\mathrm{g})\end{array}$ \\
\hline 9 & & & 4500 & & & & & 0.21 & & & & - \\
\hline 10 & 0.50 & 4.00 & .00 & .00 & 0.91 & & 9.05 & 0.21 & & 0.25 & 0.24 & 0.16 \\
\hline $11^{\mathrm{a}}$ & 125.50 & 4.01 & 45.00 & 45.00 & 0.91 & 24.1 & 9.01 & 0.21 & 0.12 & 0.25 & 0.22 & 0.16 \\
\hline $12^{\mathrm{b}}$ & 125.50 & 4.01 & 45.00 & 45.10 & 0.91 & 24.1 & 9.00 & 0.20 & 0.12 & 0.25 & 0.23 & 0.16 \\
\hline
\end{tabular}

${ }^{\text {a }}$ Another dose of TBHP/SFS redox system was added after $5 \mathrm{~h}$

${ }^{\mathrm{b}}$ The resin was vacuum distilled prior to use.

${ }^{\text {c}}$ SETAL 293 XX

Table 3. Formulations for high solid content miniemulsion polymerisations with various monomer compositions.*

\begin{tabular}{cccccccc}
\hline Run & $\begin{array}{c}\mathrm{H}_{2} \mathrm{O} \\
(\mathrm{g})\end{array}$ & $\begin{array}{c}\text { MMA } \\
(\mathrm{g})\end{array}$ & $\begin{array}{c}\text { BA } \\
(\mathrm{g})\end{array}$ & $\begin{array}{c}\text { AA } \\
(\mathrm{g})\end{array}$ & $\begin{array}{c}\text { Alkyd } \\
(\mathrm{g})\end{array}$ & $\begin{array}{c}\text { Conversion } \\
(\%)\end{array}$ & Type of Alkyd \\
\hline 13 & 118.5 & 45 & 45 & 0.9 & 25 & 97 & Unsaturated \\
14 & 55 & 45 & 0 & 0.45 & 12.5 & 99 & Unsaturated \\
15 & 55 & 0 & 45 & 0.45 & 12.5 & 95 & Unsaturated \\
16 & 118.5 & 45 & 45 & 0.9 & 25 & 96 & Saturated \\
\hline
\end{tabular}

* In all cases initiation was carried out as explained previously for Run 11. 
Table 4. Recipes for the experiments carried out by changing the monomer to reactive alkyd ratio and initiator system

\begin{tabular}{lcccccccccc}
\hline Run & $\begin{array}{c}\mathrm{H}_{2} \mathrm{O} \\
(\mathrm{g})\end{array}$ & $\begin{array}{c}\text { Dowfax } \\
(\mathrm{g})\end{array}$ & $\begin{array}{c}\mathrm{BA} \\
(\mathrm{g})\end{array}$ & $\begin{array}{c}\mathrm{MMA} \\
(\mathrm{g})\end{array}$ & $\begin{array}{c}\text { AA } \\
(\mathrm{g})\end{array}$ & $\begin{array}{c}\text { Alkyd } \\
(\mathrm{g})\end{array}$ & $\begin{array}{c}\text { ODA } \\
(\mathrm{g})\end{array}$ & $\begin{array}{c}\mathrm{KPS}(1) \\
(\mathrm{g})\end{array}$ & $\begin{array}{c}\mathrm{KPS}(2) \\
(\mathrm{g})\end{array}$ & $\begin{array}{c}\text { AIBN } \\
(\mathrm{g})\end{array}$ \\
\hline 17 & 125.0 & 4.00 & 45.00 & 45.00 & 0.91 & - & 4.6 & 0.3 & - & - \\
$18^{\mathrm{a}}$ & 116.0 & 5.00 & 45.00 & 45.00 & 0.91 & 25.0 & - & 0.15 & 0.15 & - \\
$19^{\mathrm{a}}$ & 111.0 & 5.00 & 45.00 & 45.00 & 0.91 & 25.0 & - & - & 0.15 & 0.3 \\
20 & 110.0 & 4.00 & 22.50 & 22.50 & 0.45 & 45.0 & - & - & - & 0.3 \\
$21^{\mathrm{a}}$ & 116.0 & 5.00 & 22.50 & 22.50 & 0.45 & 45.0 & - & - & 0.15 & 0.3 \\
$22^{\mathrm{a}}$ & 116.0 & 5.00 & 22.50 & 22.50 & 0.45 & 45.0 & - & 0.3 & 0.15 & - \\
\hline
\end{tabular}

${ }^{\mathrm{a}}$ The second dose of KPS (KPS(2) in $3 \mathrm{~mL}$ of water) was added with $1 \mathrm{~g}$ of Dowfax $2 \mathrm{~A} 1$ in $3 \mathrm{~mL}$ of water after $1.5 \mathrm{~h}$ from the beginning of the reaction for $1 \mathrm{~h} .{ }^{\mathrm{b}}$ The initiator system was similar to the system described in Run 10.

The general procedure followed in these experiments was as follows:

1. The alkyd resin was dissolved in the organic phase at $60^{\circ} \mathrm{C}$ under magnetic stirring for 30 minutes.

2. The required amount of surfactant was dissolved in the aqueous phase.

3. The organic phase was added slowly to the aqueous phase under gentle stirring. The mixture was then left to mix for 30 minutes.

4. The final mixture was then sonicated for 2 minutes at $80 \%$ of $600 \mathrm{~W}$ output power as this was sufficient to reach a stable droplet size.

5. The kinetically stable dispersion was transferred to the reactor, heated to the desired reaction temperature. The initiator was then added (in runs 9-12 additional initiator was added at the times indicated in Table 2).

\subsection{Characterisation}

The droplet size was measured immediately following sonication and then several hours afterward to ensure that the latex is stable for at least the time necessary to transfer it from the sonication stage to the reactor. Samples were occasionally withdrawn through a valve in the bottom of the reactor for analysis. Conversions were measured by gravimetry. Individual conversion of monomers was detected by gas chromatography (HP5890 SERIES II) and the column was a capillary column. Molecular weight was measured by Gel Permeation Chromatography (GPC) consisting of a WATERS 515 pump, automatic sample injection (WATERS 717 Plus), UV detector (WATERS 410), Differential Refractometric Detector (WATERS 410) and Light Diffusion Detector (Mini dawn Wyatt) using THF as the eluent. The first column (PLgel 5 $\mu \mathrm{m})$ was followed by three columns $(2 \times$ PLgel $5 \mu \mathrm{m}$ Mixed C

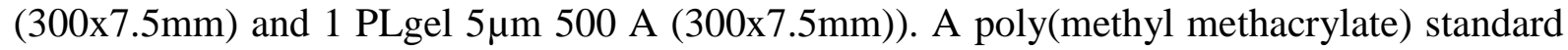
was used for calculations. Average droplet $\left(D_{d}\right)$ and particle sizes $\left(D_{p}\right)$ were measured with a particle size analyzer (MALVERN ZETASIZER $1000 \mathrm{HS}_{\mathrm{A}}$ ). Average sizes reported here are the averages of at least 5 measurements per sample. Full particle size distributions were measured with a Beckman Coulter LS 230 apparatus (static light scattering). The Critical Micellar Concentration (CMC) of the surfactant in the presence and absence of alkyd was measured by tensiometry (Krüss Processor Tensiometer K12), and the area covered by one surfactant molecule $\left(\mathrm{A}_{\mathrm{s}}\right)$ was calculated using standard methods (the experimental procedure is described in the Supporting Information). The $\mathrm{A}_{\mathrm{s}}$ of Dowfax in both cases was calculated to be $100 \AA^{2} /$ molecule, implying that the presence of alkyd does not change the nature of the 
particle surface and that the alkyd is essentially buried inside the particles. Atomic force microscopy (AFM) was used to study the nanostructure of acrylic/alkyd nanocomposite films. All AFM measurements reported here were performed with a commercial instrument (NTEGRA, NT-MDT, Moscow, Russia) operating in intermittent contact mode using a silicon cantilever (NT-MDT). The nominal resonant frequency $f_{o}$ of the cantilever is about $115-150 \mathrm{kHz}$ and its spring constant $k$ is about $10 \mathrm{~N} \mathrm{~m}^{-1}$. The "free" amplitude of the cantilever, $A_{o}$ (corresponding to oscillation in air), was fixed at $241 \mathrm{~nm}$. The setpoint amplitude, $A_{s p}$ (corresponding to the amplitude when the tip is in contact with the sample surface), was kept at $122 \mathrm{~nm}$, thus making the setpoint ratio, $A_{s p} / A_{o}$, equal to 0.5 for all measurements. The setpoint ratio determines the force of the AFM tip on the surface and can affect the apparent topography soft samples ${ }^{31}$. Films were cast on a polypropylene substrate using a $40 \mu \mathrm{m}$ hand-held bar coater and allowed to dry overnight at a temperature of $22 \pm 1^{\circ} \mathrm{C}$ and a relative humidity of $55 \pm 1 \%$. The dried films for AFM analysis were about $20 \mu \mathrm{m}$ thick and were rinsed before scanning.

The degree of grafting of the polyacrylate to the alkyd resin, DG, was measured by the method described by Tsavalas et al. ${ }^{5}$. Selective extraction was performed in a Soxhlet extractor with diethyl ether as solvent. Vacuum-dried samples were weighed in filter paper of known weight and inserted into the extractor. Samples were extracted for durations of at least $24 \mathrm{~h}$ at the solvent boiling point $\left(40^{\circ} \mathrm{C}\right)$. Wet samples were then removed, dried and the residual weight was measured. The residual weight after extraction was assumed to be homoacrylic polymer. DG was calculated as:

$$
\begin{aligned}
\text { DG }(\%) & =\frac{\text { Acrylic polymer in hybrid }}{\text { Total polyacrylic }} \times 100 \\
& =\frac{\text { Total amount of solid } \times \text { Acrylic w eight fraction- Residual weight }}{\text { Total amount of solid } \times \text { Acrylic weight fraction }} \times 100
\end{aligned}
$$

Where the residual weight is pure homoacrylic polymer and the acrylic weight fraction is defined as

Acrylic weight fraction $=\frac{\text { Total monomer } \times \text { Fractional conversion }}{\text { Total monomer } \times \text { Fractional conversion }+ \text { Alkyd }+ \text { Initiator }+ \text { Surfactant }}$

\section{Results and discussion}

\subsection{Influence of the alkyd on polymerisation rate and monomer conversion}

The Runs 1-3 in Table 1 were used to identify formulations that provided a reasonable $N_{p} / N_{d}$ ratio for low levels of alkyds. The results of these runs are summarised in Table 5. An increase of particle diameter by about $30 \mathrm{~nm}$ compared to the initial droplet diameter $(70 \mathrm{~nm}$ to $100 \mathrm{~nm}$ ) was observed in the first two runs. It is likely that this was caused by the absence of a sufficient quantity of hydrophobe. Thus, the small quantity of alkyd resin was insufficient to control the Ostwald ripening. Adding 5wt $\%$ of ODA in the next run and controlling the sonication time to maintain the droplet size around $100 \mathrm{~nm}$, enabled us to make droplets of $104 \mathrm{~nm}$, and to maintain an $\mathrm{N}_{\mathrm{p}} / \mathrm{N}_{\mathrm{d}}$ ratio of 1.06 . 
Table 5. Droplet and particle sizes in Runs 1 to 3.

\begin{tabular}{cccccccc}
\hline Run & $\begin{array}{c}\text { Alkyd } \\
(\mathrm{wt} \%)\end{array}$ & $\begin{array}{c}\text { ODA } \\
(\mathrm{wt} \%)\end{array}$ & $\begin{array}{c}\mathrm{D}_{\mathrm{d}} \\
(\mathrm{nm})\end{array}$ & $\begin{array}{c}\mathrm{D}_{\mathrm{p}} \\
(\mathrm{nm})\end{array}$ & $\mathrm{N}_{\mathrm{p}} / \mathrm{N}_{\mathrm{d}}$ & $\begin{array}{c}\text { Total Solid } \\
\text { Content }(\%)\end{array}$ & $\begin{array}{c}\text { Final Monomer } \\
\text { Conversion }(\%)\end{array}$ \\
\hline 1 & 0.6 & 0 & 70 & 100 & 0.28 & 20 & 100 \\
2 & 2.6 & 0 & 65 & 98 & 0.23 & 20 & 100 \\
3 & 2.5 & 5 & 104 & 102 & 1.1 & 21 & 100 \\
\hline
\end{tabular}

Using this initial formulation as a starting point, a second series of runs (runs 4-8 in Table 1) was conducted to explore the effect of increasing the alkyd content from 2.5 to $25 \%$. Run 3 was not repeated and a control run with $0 \%$ alkyd was done instead (run 4).

The evolution of the droplet size as a function of sonication time and the viscosity of the organic phase as a function of alkyd content are shown in Figure 1. It can be seen here that as the alkyd content increases, the viscosity and average droplet size also increase. As the viscosity of the organic phase increases, more energy is needed to rupture the droplets at a fixed overall solid content. In addition, the organic phase becomes increasingly hydrophobic and it becomes more difficult to overcome the energy barrier opposing the creation of a large surface area. The end result is that the surface area available for the capture of the aqueous phase free radicals drops as the alkyd content increases. One would expect that this would lead to a reduction in the rate of polymerisation as the alkyd content increases, and this is what is observed for Runs 4-8 in Figure 2.
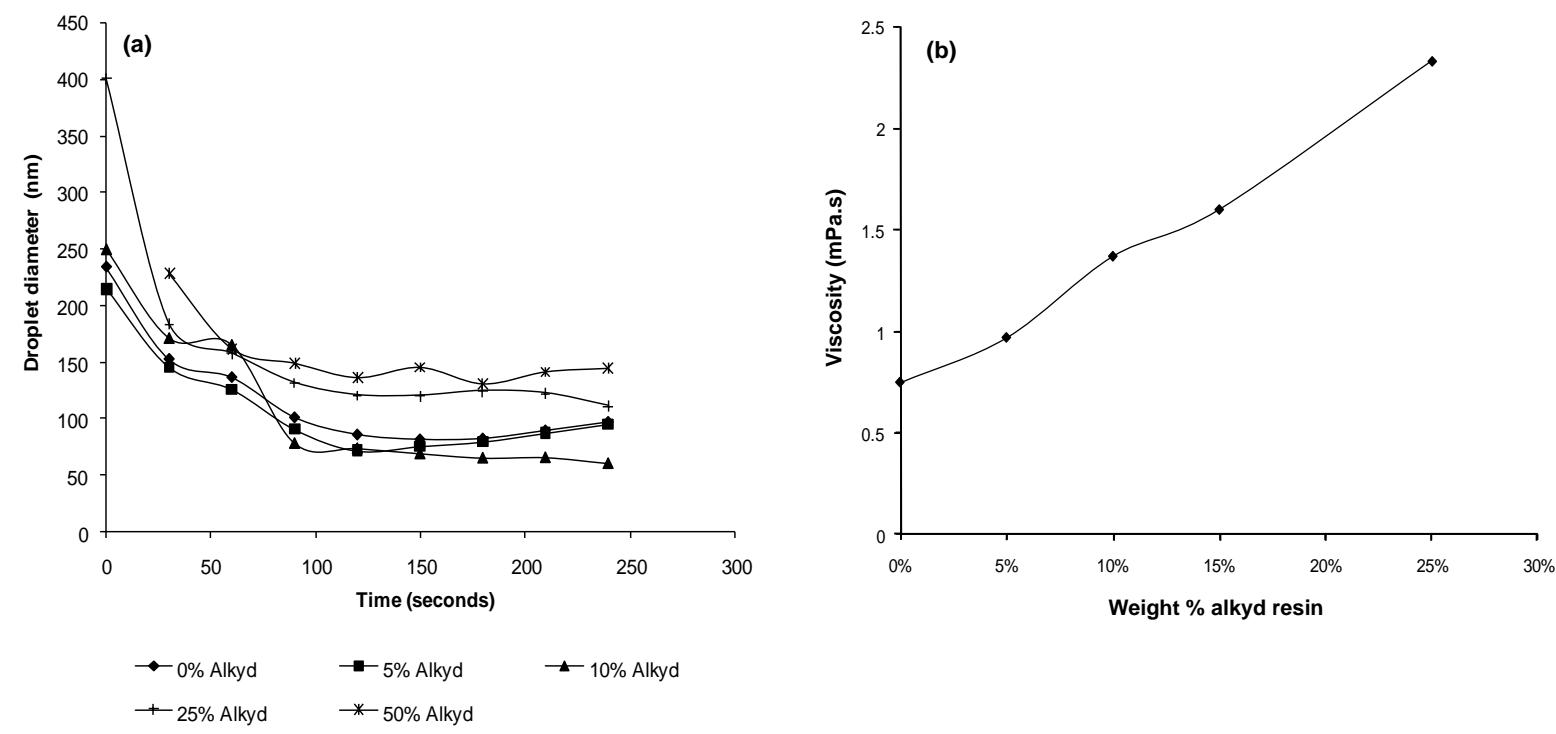

Figure 1. (a) Evolution of the droplet diameter as a function of time, and (b) the viscosity of the organic phase as a function of alkyd content. 


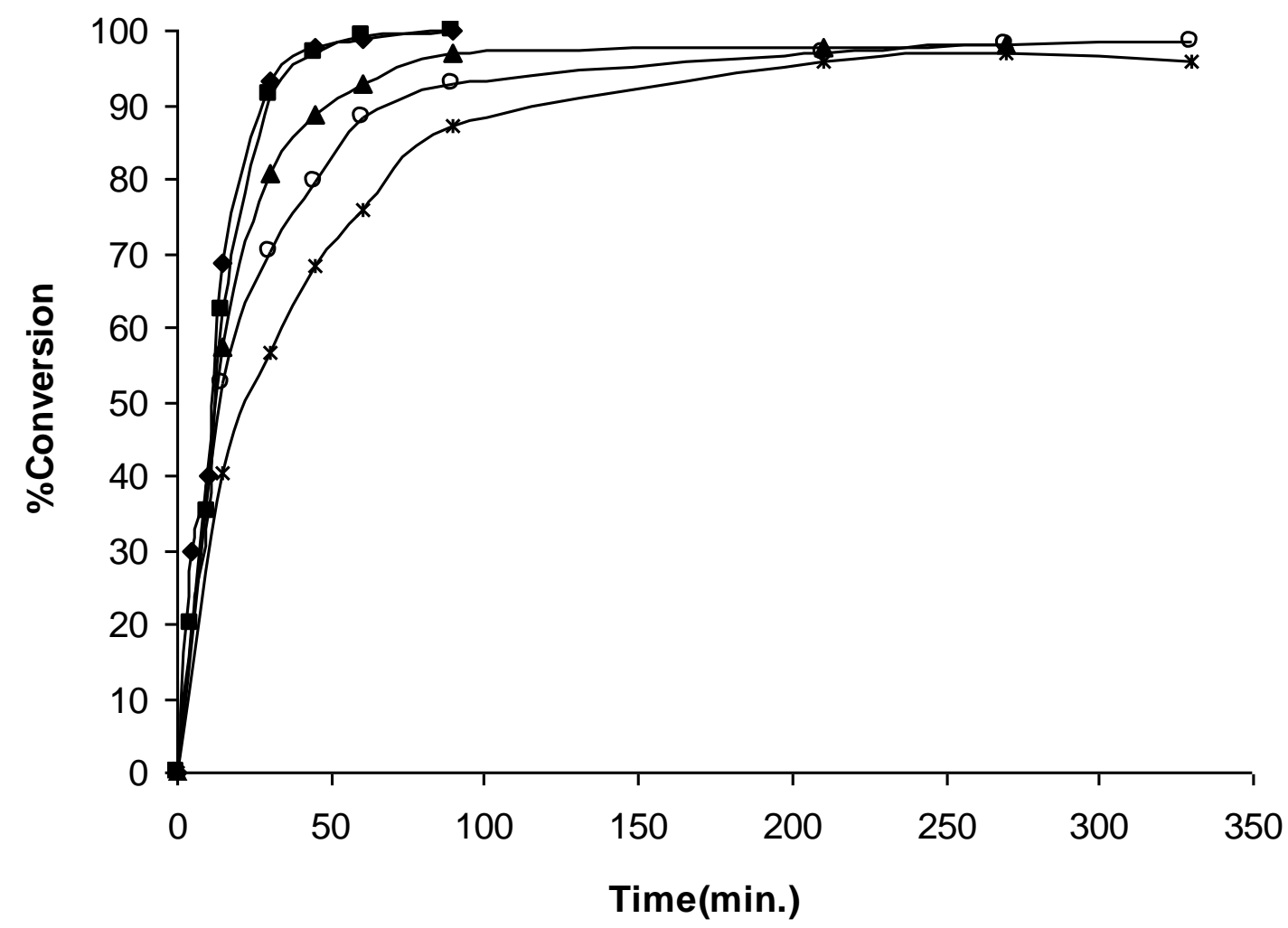

$\multimap 0 \%$ Alkyd $\rightarrow-5 \%$ Alkyd $\multimap 10 \%$ Alkyd $\multimap-15 \%$ Alkyd $\rightarrow-25 \%$ Alkyd

Figure 2. Monomer conversion versus time curves for varying alkyd contents in runs 4-8 (c.f. Table 1).

Although $\mathrm{N}_{\mathrm{p}} / \mathrm{N}_{\mathrm{d}}$ remains within a reasonable bound around one (secondary nucleation seems to be more important at higher alkyd contents, but this will be discussed below), complete monomer conversion was achieved only with $2.5 \mathrm{wt} \%$ of alkyd resin or less. The runs performed with a higher amount of alkyd exhibited a limiting conversion as shown in Figure 2 and Figure 3. 


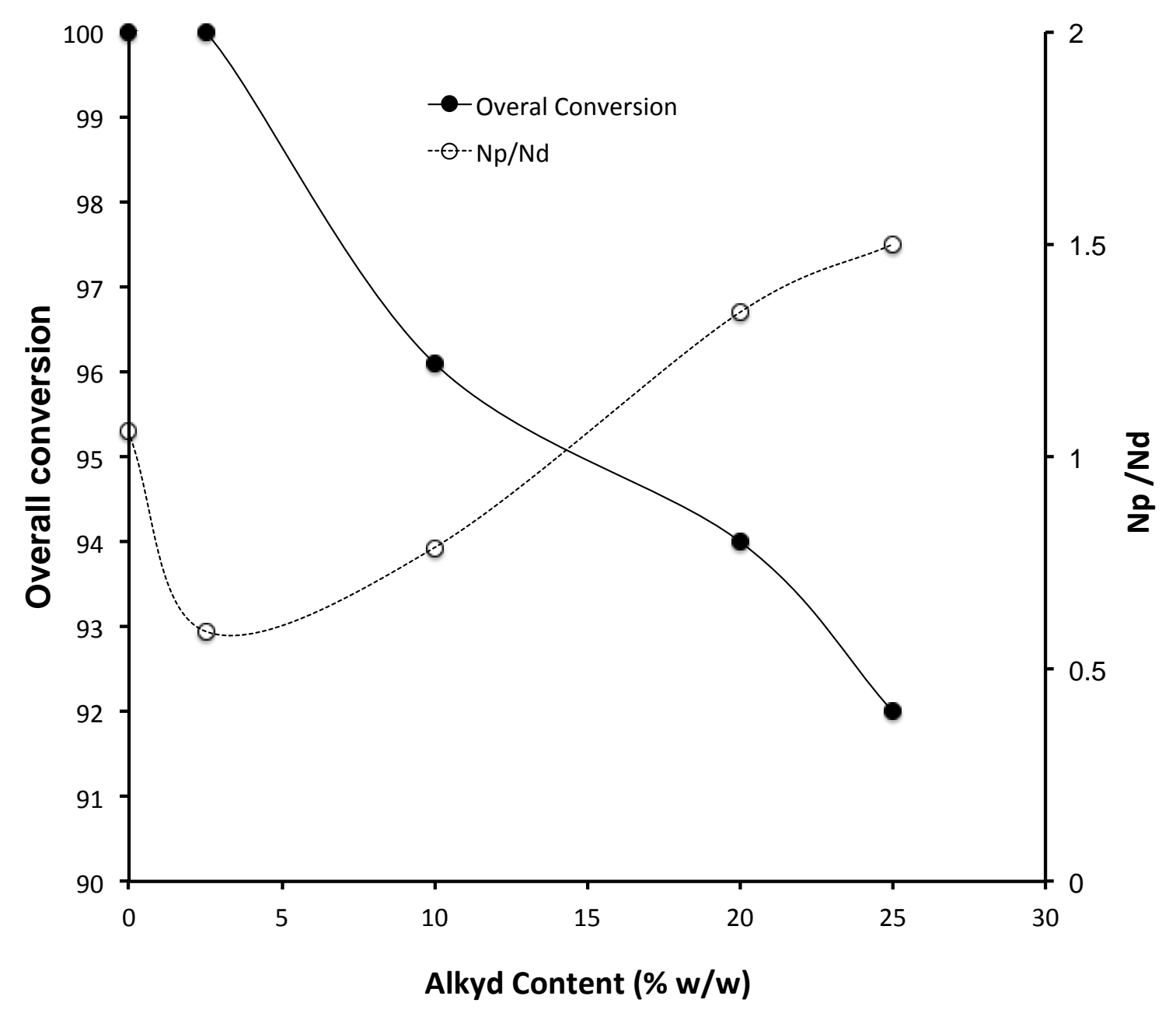

Figure 3. Effect of alkyd quantity on final overall monomer conversion and ratio of the number of particles to number of droplets.

\subsection{Can we overcome the limiting conversion?}

Two strategies were developed in an attempt to overcome this limiting conversion: (1) increasing the radical flux in the later stages of the experiment and (2) extra purification of the alkyd. To test the idea that the radical flux during polymerisation might be inadequate, due to the presence of impurities in the system for example, the initiator system was modified in different ways as seen in Table 2. In addition to the initial dose of initiator (KPS(1)), a second dose (KPS(2) and $\mathrm{NaHSO}_{3}$ ) was added semi-continuously under redox conditions for one hour after the first two hours of the reaction (Run 9), similar to the approaches described by Minari et al. ${ }^{13}$ and Goikoetxea et al. ${ }^{14}$. Despite the increased radical flux in this run, Table 6 shows that no considerable increase of monomer conversion was observed at alkyd levels of $25 \mathrm{wt} \%$. Therefore a third dose of redox initiator was added in Runs 10 to 12 . The third dose was added as a single shot after $3 \mathrm{~h}$ of reaction, and the temperature was increased to $80{ }^{\circ} \mathrm{C}$ for an additional hour. Once again, despite these changes in the rate of generation of free radicals, the final monomer conversion was still only $92 \%$ in the presence of $25 \mathrm{wt} \%$ of alkyd resin (in other words, unchanged to within the limits of experimental variability). Similarly, another dose of TBHP/SFS redox initiator added after $5 \mathrm{~h}$ in the next run (Run 11) did not appreciably change the final conversion. In a final experiment in the series (Run 12), the alkyd resin was vacuum distilled before use in order to remove xylene and any other light components that might be present in the alkyd, but that are difficult to detect by GC or NMR 
analyses $^{32-34}$. Indeed, solvents are known to influence the rate of free radical polymerisation and can account for the limiting conversion. As can be seen from Table 6, vacuum distilling the alkyd prior to the miniemulsification process resulted in an increase of the final conversion to $96 \%$.

Table 6. Droplet size, particle size, $\mathrm{N}_{\mathrm{p}} / \mathrm{N}_{\mathrm{d}}$ ratio and monomer conversion for Runs 9-12.

\begin{tabular}{ccccccc}
\hline Run & $\begin{array}{c}\text { Alkyd } \\
(\mathrm{wt} \%)^{\mathrm{a}}\end{array}$ & $\begin{array}{c}\mathrm{D}_{\mathrm{d}} \\
(\mathrm{nm})\end{array}$ & $\begin{array}{c}\mathrm{D}_{\mathrm{p}} \\
(\mathrm{nm})\end{array}$ & $\mathrm{N}_{\mathrm{p}} / \mathrm{N}_{\mathrm{d}}$ & $\begin{array}{c}\text { Solid content } \\
(\%)\end{array}$ & $\begin{array}{c}\text { Monomer } \\
\text { Conversion }(\%)\end{array}$ \\
\hline 9 & & 147 & 130 & 1.3 & 46 & 92 \\
10 & 25 & 147 & 125 & 1.4 & 46 & 92 \\
11 & & 145 & 123 & 1.4 & 46 & 92 \\
12 & & 130 & 117 & 1.2 & 48.4 & 96 \\
\hline
\end{tabular}

${ }^{\mathrm{a}}$ In weight percent based on monomers

In summary, none of the modifications discussed here, nor additional trials outlined in Table S1 in the Supporting Information, such as lowering the total solid content, lowering the alkyd quantity to $10 \mathrm{wt} \%$, using oil-soluble initiators or adding MMA in a semi-continuous way in the presence of KPS or lauryl peroxide (an organosoluble initiator), allowed us to increase the overall conversion. This suggests that the limiting conversion is more likely to be due to either chemical or physical interactions between the acrylic and the alkyd components, rather than a lack of free radicals or purity of the alkyd. In order to get a better understanding of this aspect, we looked at the individual monomer conversions, and specifically which of the acrylic monomers was more effective in participating in the grafting process with the alkyd used in this study.

\subsection{Individual monomer conversions and degree of grafting}

In order to better understand the interaction of the alkyd resin with the monomers, and to look into the limiting monomer conversion in more detail, we investigated the individual monomer conversions in Runs 4-8. The individual monomer conversions for MMA and BA in the absence of alkyd, and in the presence of $5 \mathrm{wt} \%$ and $25 \mathrm{wt} \%$ alkyd are shown in Figure $4 \mathrm{a}, \mathrm{b}$ and c respectively. 

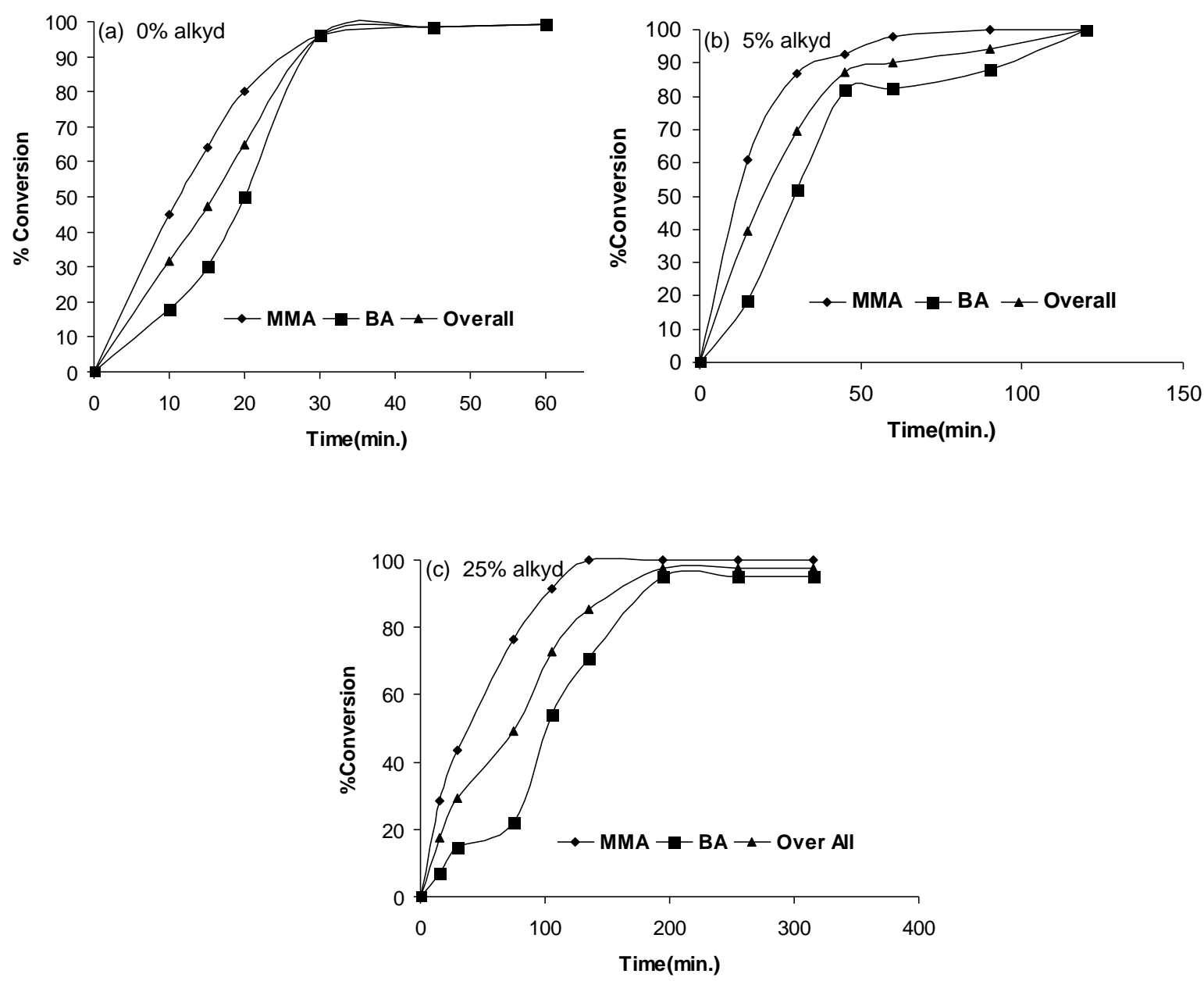

Figure 4(a) Individual monomer conversions versus time for miniemulsion polymerisation reactions conducted in the absence of alkyd. (b) Individual and overall monomer conversions in the presence of $5 \mathrm{wt} \%$ unsaturated alkyd resin. (c) Individual and overall monomer conversions in the presence of $25 \mathrm{wt} \%$ unsaturated alkyd resin.

If one looks at Figure 4(b) and (c), it is apparent that like in Figure 4(a), MMA reacts completely in all cases. It therefore appears that the limiting conversion seen in these last two graphs is related to the incomplete conversion of BA. This is quite surprising and interesting when one considers that $\mathrm{BA}$ is the more effective monomer in the grafting reaction. When the structure of BA is compared to that of MMA, it can be seen that butyl acrylate presents far fewer steric hindrances than MMA. Therefore its ability to undergo addition through double bonds is high. Schork et al. ${ }^{4}$ have shown that a fairly low $\mathrm{k}_{\mathrm{tr}} / \mathrm{k}_{\mathrm{P}}$ (the ratio of transfer rate to propagation rate constants) value could be observed for the BA/alkyd system, and this implies that the mode of attack of a BA radical to the alkyd is more likely through direct addition to a double bond of the resin rather than through chain transfer. The hypothesis that essentially only BA is grafted to this particular alkyd resin was confirmed by measuring the degree of grafting of the alkyd for different monomer compositions.

To do so, different miniemulsions of various monomer compositions were run with the same basic formulation and solid content as in Run 8. The final products were then fractionated using Soxhlet extraction to determine the acrylic degree of grafting and the results of this procedure are shown in Table 7 . In the case of PBA and $25 \%$ alkyd, high gel content in the 
final product due to the well-known transfer to polymer exhibited by butyl acrylate radicals affects the numerical value of grafting. Nevertheless, there appears to be non-negligible levels of grafting between PBA and alkyd, whereas the grafting between PMMA and alkyd was $0 \%$. This trend of grafting is in agreement with Schork et al. ${ }^{4}$, who observed $100 \%$ grafting for BA and about $40-50 \%$ grafting for MMA, although the numerical values are different. The difference of numerical values could be due to the type of alkyd (i.e. the number of double bonds and hydrophobicity differences). Nevertheless, the results presented in the current paper clearly show that there is grafting of the copolymer to the unsaturated alkyd, and this takes place essentially with BA. It should be noted that the apparent inconsistency in Table 7 that suggests that the BA is less grafted in the case where it is the only monomer is most likely due to the drawback of the selective extraction method. In each case the total solid content is fixed (50\%). In the case of BA only, the fraction dissolved in the organic phase is less compared to MMA/BA system (The \% PBA is high in BA only and PBA is less soluble in Diethyl Ether). Therefore the grafting measured by the selective extraction method is not $100 \%$ accurate.

Table 7. Selective extraction data of hybrid latex

\begin{tabular}{ccccc}
\hline $\begin{array}{c}\text { Monomer } \\
\text { composition }\end{array}$ & $\begin{array}{c}\text { Total amount } \\
\text { of solid }(\mathrm{g})\end{array}$ & $\begin{array}{c}\text { Acrylic weight } \\
\text { fraction }(\%)\end{array}$ & $\begin{array}{c}\text { Residual weight }(\mathrm{g}) \\
\text { after solvent } \\
\text { extraction }\end{array}$ & $\begin{array}{c}\text { Degree of } \\
\text { Grafting }(\%)\end{array}$ \\
\hline $\begin{array}{c}\text { MMA/BA/AA } \\
(49.5 / 49.5 / 1)\end{array}$ & 6.1 & 77.6 & 1.7 & 64 \\
BA & 6.9 & 77.6 & 3.6 & 33 \\
MMA & 6.2 & 78.5 & 5.1 & 0 \\
\hline
\end{tabular}

The grafting was further characterised by GPC and also confirmed by ${ }^{1} \mathrm{H}$ and ${ }^{13} \mathrm{C}$ NMR analyses, both of which showed that the double bonds of the alkyd were consumed during polymerisation and hence indicated chemical incorporation of alkyd into the growing copolymer (see Supporting Information). The GPC chromatograms of pure alkyd resin and hybrid latex of 25\% alkyd are shown in Figure 5 (a) and (b) respectively. The results are summarised in Table 8 and it is clear that the alkyd resin is not well-defined and has a broad molecular weight distribution.

Although the high molecular weight region is masked by the copolymer peak, two low molecular weight peaks of alkyd resin can be clearly observed. We considered only the peak with the weight average $M_{\mathrm{w}}$ of 1843 (peak of $2027 \mathrm{~g} \mathrm{~mol}^{-1}$, Figure 5(a)) and compared the peak area and height of the same peak in Figure 5 (b) $\left(M_{\mathrm{w}}\right.$ of 1828 and peak value of $2015 \mathrm{~g}$ $\mathrm{mol}^{-1}$ ) to verify the chemical incorporation of alkyd to copolymer. According to this analysis, we found that approximately $33 \%$ of the alkyd in this peak was grafted to the copolymer.

In summary, an analysis of the individual monomer conversion data and grafting experimental results have led to a better understanding of the polymerisation process. It can be concluded that while the grafting between the alkyd and copolymer appears to take place mainly via reaction with the $\mathrm{BA}$, the overall limiting monomer conversion is due to the low $\mathrm{BA}$ conversion. One possible reason for this is that the polymer and alkyd phase can phase separate during the later stages of the reaction, and the BA can partition between these two phases. This type of phase separation has been observed in the case of the encapsulation of an oil phase with an acrylic polymer where a capsule containing a core of oil (e.g. hexadecane) surrounded by an acrylic polymer shell was obtained by polymerising what were originally homogeneous droplets. If such a phase separation takes place in the current case, then the 
growing free radicals, which would be in the polymer phase of the particle would not be able to "access" the BA in the alkyd phase, resulting in an incomplete reaction. Otherwise, Heiskanen et al. ${ }^{20}$ noted that MMA/BA/Alkyd systems behaved differently than MMA/Alkyd systems, and that at alkyd contents above 30 in the MMA/Alkyd system the overall conversion was lower than in the mixed monomer system. They also noticed that not all of the double bonds in the alkyd are consumed during the polymerisation step with the acrylic resins. Their work showed that in the case of a BA/MMA/Alkyd hybrid there were 3 observable glass transitions: between -20 to $-23^{\circ} \mathrm{C}, 34-41^{\circ} \mathrm{C}$, and $50-70^{\circ} \mathrm{C}$, suggesting the presence of a BA-rich copolymer, a hybrid with the alkyd and an MMA-rich copolymer. The presence of these three different products suggests that there is some physical separation occurring in the droplet/particles. If the MMA partitions closer to the outside of the particle due to its higher hydrophilicity (vis à vis BA), and BA in the core with the alkyd, then it is possible that since the MMA polymerises first, we get a highly viscous outer shell surrounding a less viscous, but highly hydrophobic inner core making it difficult for free radicals to penetrate and consume the residual BA. This interpretation is in line with the physical interpretation proposed by the group of Schork ${ }^{25,30}$. Minari et al. ${ }^{13}$ seem to agree with this interpretation and found that using highly hydrophobic radicals issued from the redox decomposition of TBHP/AscA were more efficient in reducing the residual acrylic monomer levels than more hydrophilic radicals, and that the alkyd resin acts as a "radical sink". 

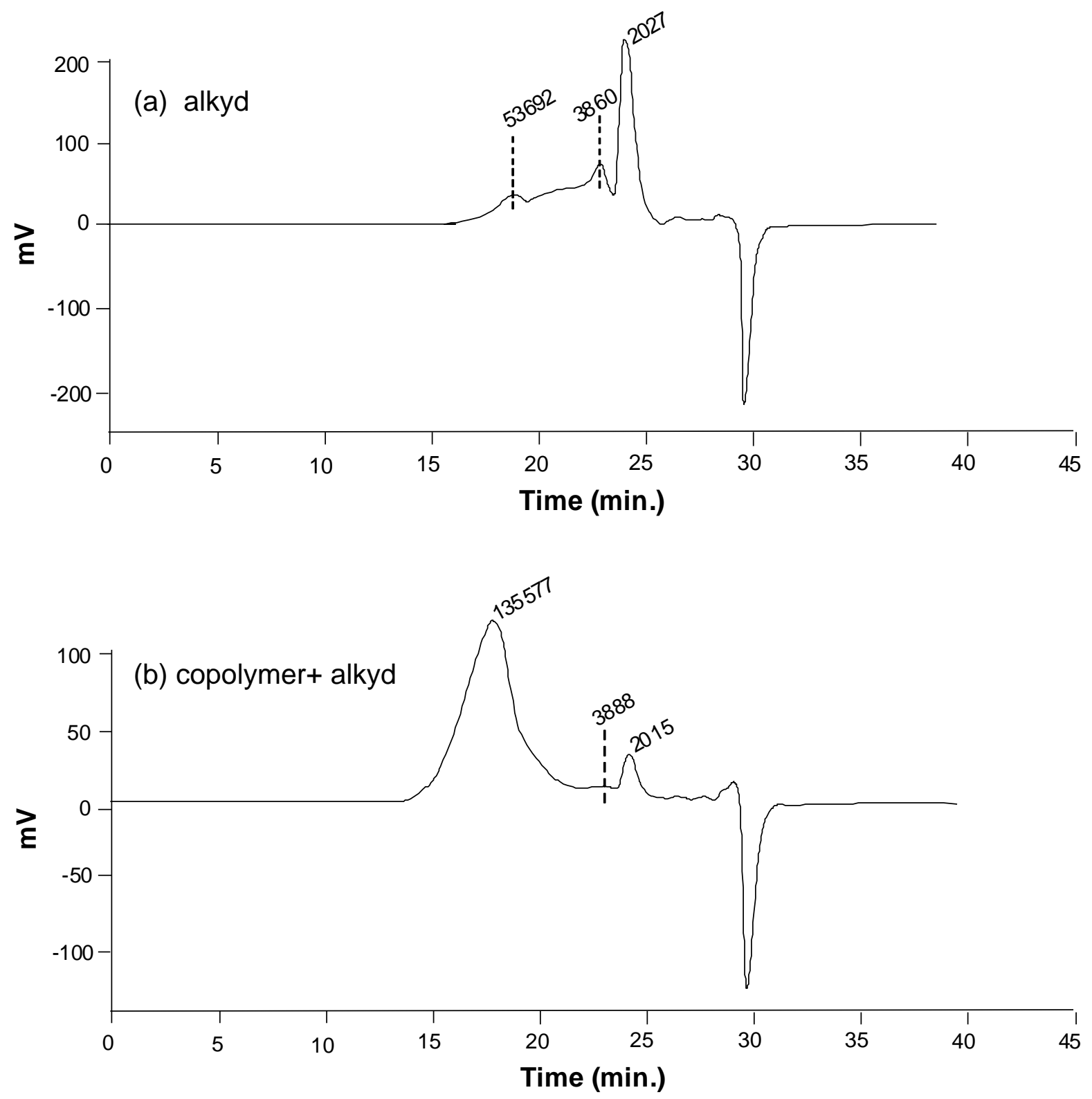

Figure 5. (a) GPC of the Setal 293 unsaturated alkyd resin. (b) GPC of copolymer with 25\% alkyd resin

Table 8. GPC analysis of the Setal 293 unsaturated alkyd resin

\begin{tabular}{cccccccc}
\hline Peak & \multirow{2}{*}{$M_{\mathrm{n}}$} & $M_{\mathrm{w}}$ & $M_{\mathrm{z}}$ & $M_{\mathrm{z}+1}$ & $M_{\mathrm{w}} / M_{\mathrm{n}}$ & Area $\left(\mu \mathrm{V}^{*} \mathrm{sec}\right)$ & $\%$ Area \\
\hline 53692 & 68,570 & 108,710 & 25,7160 & 613,150 & 1.59 & 3410183 & 13.6 \\
3860 & 6,470 & 10,360 & 16,250 & 21,480 & 1.60 & 10691733 & 42.6 \\
2027 & 1,760 & 1,840 & 1,920 & 1,980 & 1.05 & 10972102 & 43.8 \\
\hline
\end{tabular}


Table 9. GPC analysis of copolymer with $25 \%$ alkyd resin

\begin{tabular}{cccccccc}
\hline $\begin{array}{c}\text { Peak } \\
\text { Mass }\end{array}$ & $M_{\mathrm{n}}$ & $M_{\mathrm{w}}$ & $M_{\mathrm{z}}$ & $M_{\mathrm{z}+1}$ & $M_{\mathrm{w}} / M_{\mathrm{n}}$ & $\begin{array}{c}\text { Area } \\
\left(\mu \mathrm{V}^{*} \mathrm{sec}\right)\end{array}$ & $\%$ Area \\
\hline 135,577 & 67,720 & 44,880 & $4,972,680$ & $18,434,900$ & 6.58 & $22,832,294$ & 88.8 \\
3,888 & 3,970 & 4,210 & 4,450 & 4,700 & 1.06 & 968,402 & 3.8 \\
2,015 & 1,730 & 1,830 & 1,910 & 1,990 & 1.06 & $1,899,939$ & 7.4 \\
\hline
\end{tabular}

\subsection{Variation of $\mathbf{N}_{p} / \mathbf{N}_{d}$ with monomer conversion}

Next the extent to which there is a one-to-one copying of emulsion droplet diameter to polymer particle diameter is investigated through analysis of the $\mathrm{N}_{\mathrm{p}} / \mathrm{N}_{\mathrm{d}}$ ratio throughout the polymerisation process. Figure 6 illustrates the variation of $\mathrm{N}_{\mathrm{p}} / \mathrm{N}_{\mathrm{d}}$ with monomer conversion for Run 12 containing $25 \mathrm{wt} \%$ of the vacuum-distilled alkyd resin. It is obvious that $\mathrm{N}_{\mathrm{p}} / \mathrm{N}_{\mathrm{d}}$ increases after about $45 \%$ monomer conversion during the polymerisation of this hybrid system, strongly suggesting the occurrence of some type of secondary nucleation of emulsion particles. It should be recalled that we have added different doses of initiator during polymerisation; thus secondary nucleation could be promoted by the intermittent addition of initiator, however as the second and third shots are added at hour 2 and hour 3 respectively (where the conversions are approximately 85 and $95 \%$ respectively), the increase in $\mathrm{N}_{\mathrm{p}} / \mathrm{N}_{\mathrm{d}}$ cannot be attributed to additional initiator (alone).

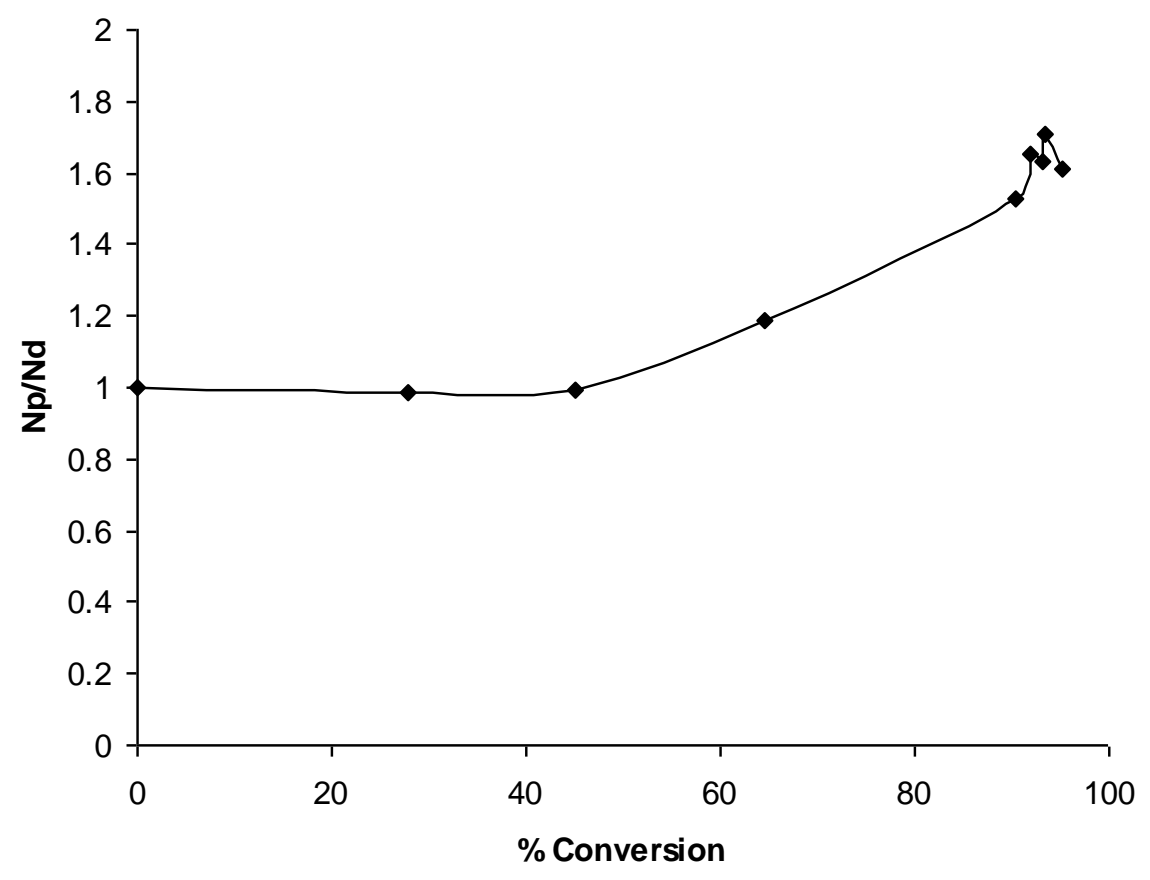

Figure 6. Variation of $\mathrm{N}_{\mathrm{p}} / \mathrm{N}_{\mathrm{d}}$ with monomer conversion for Run 12

In order to clarify this possibility and to shed more light on the effect of the amount of alkyd on $\mathrm{N}_{\mathrm{p}} / \mathrm{N}_{\mathrm{d}}$, another series of experiments identical to runs 4-8 was performed but using the vacuum-distilled alkyd resin (vacuum distilling appeared to help increase - slightly - the final conversion in run 12). The only parameter that is changing in this series of experiments is the quantity of alkyd resin. The changes of properties of initial droplets and the variation of final monomer conversion with increasing alkyd quantity are summarised in Table 10. 
Table 10. Influence of alkyd content on various reaction related parameters (Runs 4-8 with vacuum distilled resin, Table 1).

\begin{tabular}{cccccc}
\hline $\begin{array}{c}\text { Alkyd content } \\
\text { (wt\% on } \\
\text { monomers) }\end{array}$ & $\begin{array}{c}\text { Droplet } \\
\text { Size }(\mathrm{nm})\end{array}$ & $\begin{array}{c}\text { Final Particle } \\
\text { Size }(\mathrm{nm})\end{array}$ & $\mathrm{N}_{\mathrm{p}} / \mathrm{N}_{\mathrm{d}}$ & $\begin{array}{c}\text { Particle } \\
\text { Coverage by } \\
\text { Surfactant }(\%)\end{array}$ & $\begin{array}{c}\text { Viscosity of droplet } \\
\text { phase (mpa.s) } \\
\text { at } 100 \mathrm{~s}^{-1}\end{array}$ \\
\hline 0 & 79 & 104 & 0.4 & 20 & 0.75 \\
5 & 96 & 98 & 0.9 & 23 & 0.97 \\
10 & 107 & 98 & 1.3 & 25 & 1.37 \\
15 & 119 & 105 & 1.4 & 26 & 1.60 \\
25 & 134 & 116 & 1.6 & 28 & 2.33 \\
\hline
\end{tabular}

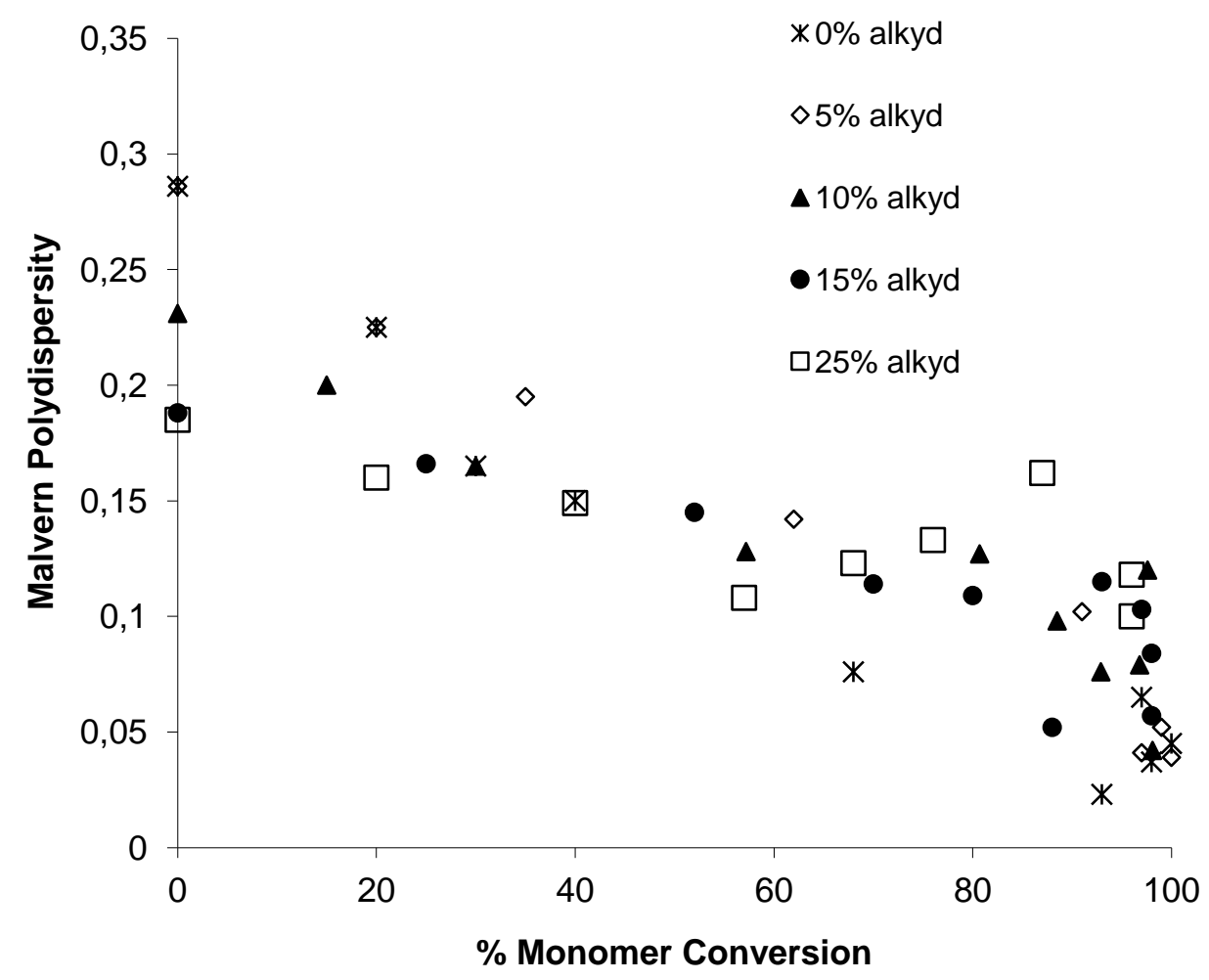

Figure 7. Variation of polydispersity index with monomer conversion for a series of miniemulsion polymerisation reactions performed according to the recipes of Table 1 using a vacuum-distilled resin.

The variation of the polydispersity ${ }^{1}$ with monomer conversion relevant to the above experiments is illustrated in Figure 7. It can be seen that the initially broad droplet size distributions become narrower after approximately 50\% monomer conversion. In fact, as the quantity of alkyd increases, the initial droplet size distribution appears to be narrower. As illustrated in Figure S4 of the Supporting Information, the dependence of droplet size varies as the dispersed phase viscosity to the power of 0.4 during sonication. It is possible that at the higher viscosities associated with the higher levels of alkyd, the cavitation due to

\footnotetext{
${ }^{1}$ N.B. here the polydispersity is a value supplied by the Malvern Instruments software. Values of approximately 0.1 or les scan be considered reasonably narrow; above 0.2 , the particle/droplet sizes must be treated with caution since the size distributions can no longer be treated as narrow.
} 
ultrasonication does not create the very small $(<40$ or $50 \mathrm{~nm})$ droplets that are created at lower viscosities (see section 3.5 below). The increase of particle size compared to the initial droplet size, coupled with a rapid narrowing of initial droplet size distribution in the absence of alkyd, suggests the disappearance of a considerable fraction of very small droplets. We will return to this point below.

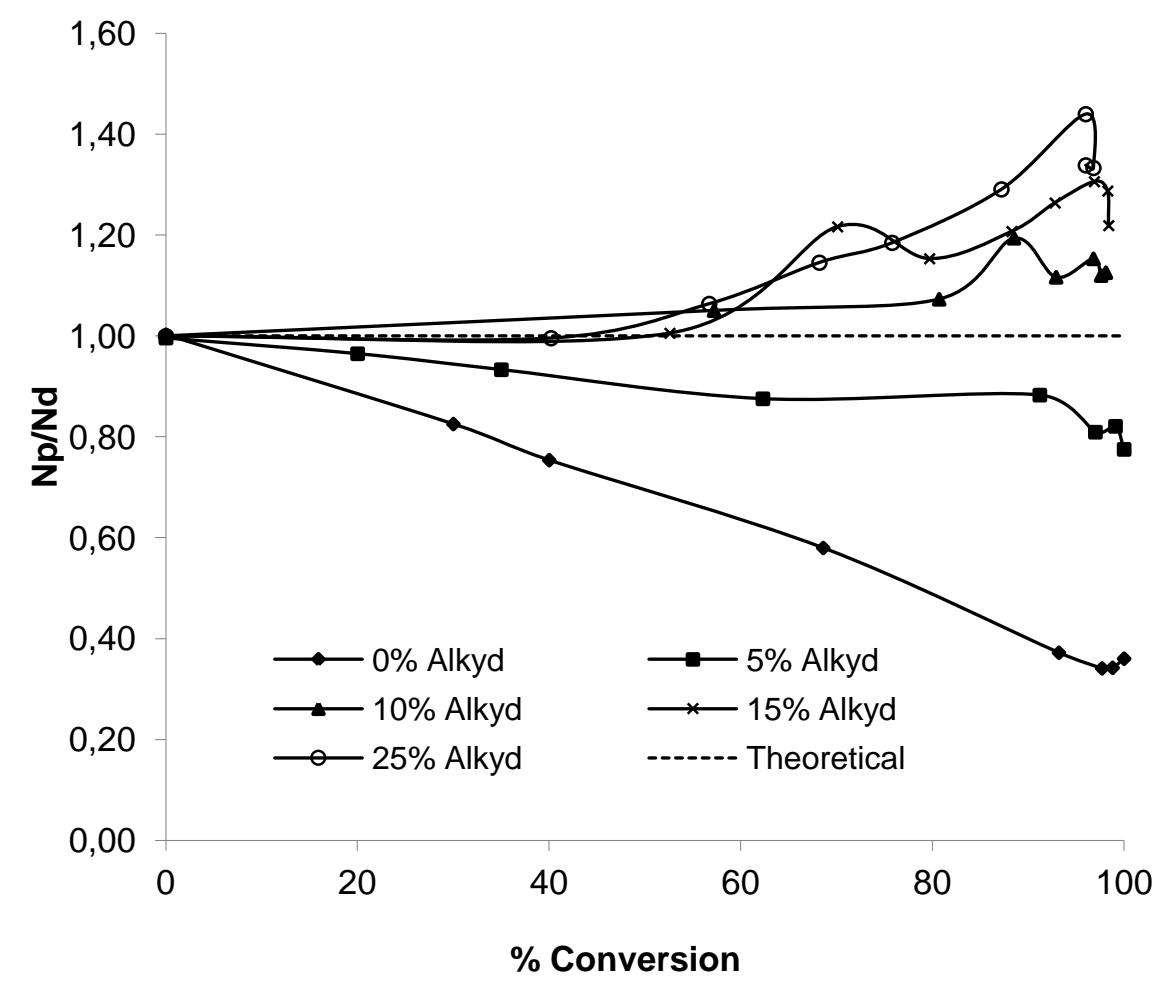

Figure 8. Variation of $\mathrm{N}_{\mathrm{p}} / \mathrm{N}_{\mathrm{d}}$ with conversion for increasing alkyd quantities according to the recipes of Table 1 using a vacuum-distilled resin.

The variation of $\mathrm{N}_{\mathrm{p}} / \mathrm{N}_{\mathrm{d}}$ with increasing alkyd quantity as a function of conversion during the polymerisation (with all other quantities remaining unchanged) is shown in Figure 8 . We observe two distinct behaviours: one for 0 and $5 \%$ alkyd where $\mathrm{N}_{\mathrm{p}} / \mathrm{N}_{\mathrm{d}}$ is monotonically decreasing and always less than one; and a second behaviour for higher alkyd contents where $\mathrm{N}_{\mathrm{p}} / \mathrm{N}_{\mathrm{d}}$ increases for conversions higher than $50 \%$. We will first consider the case of the polymerisations performed without alkyd or with $5 \%$ alkyd. In the presence of $5 \%$ alkyd, the $\mathrm{N}_{\mathrm{p}} / \mathrm{N}_{\mathrm{d}}$ ratio was closer to one compared to the polymerisation performed without alkyd, and this implies that the hydrophobic character of the organic phase is significantly increased. As a result, the stability of the very small droplets is increased. In order to investigate this, the hydrophobic effect of hexadecane and ODA was studied and compared to the use of an equivalent amount of alkyd as the hydrophobe. As illustrated in Figure 9, similar initial droplet sizes of about $80 \mathrm{~nm}$ are obtained for equivalent weight fractions of three different hydrophobes (admittedly the mole fractions will be slightly different for ODA and hexadecane, but it is difficult to compare alkyd resins on a molar basis). However, as the polymerisation proceeds, the average particle size increases by approximately $25 \mathrm{~nm}$ when hexadecane and ODA were used as the hydrophobe during the first hour of polymerisation, but remained relatively constant when the alkyd was used alone. 


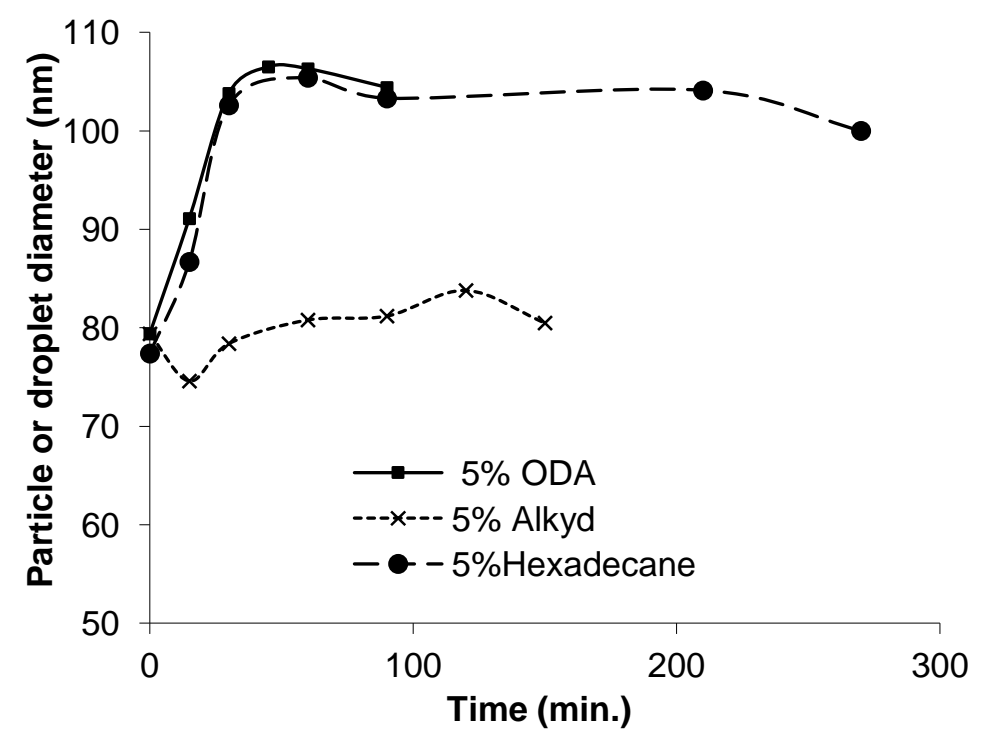

Figure 9. Variation of droplet and particle size with time for thee different hydrophobes and the same monomer formulation used in all other experiments.

This comparison clearly indicates that the chemical potential of the alkyd (unsaturated) and monomer is higher than that of a mixture of the monomers and either of hexadecane or ODA; hence low levels of alkyd provide a better stabilisation than hexadecane or ODA. Sood and Awasthi ${ }^{12}$ have shown theoretically that in a given system with a particular amount of hydrophobe, and depending on the degree of non-ideality of mixing between the monomer and the hydrophobe, there exists a minimum stable diameter in the reactor. They demonstrated with data from the literature that for the same amount of different hydrophobes (hexadecane and hexadecanol) the minimum stable diameter of styrene is 117 and $187 \mathrm{~nm}$, respectively, because hexadecanol is more non-ideal than hexadecane. According to these authors, the interaction parameter $(\chi)$ for hexadecane and styrene is equal to 0 and for hexadecanol and styrene it is 1.69. Based on this difference of interaction parameters, they showed that droplets with a diameter greater than the minimum stable diameter are stable because they fulfil the chemical potential requirement for stability.

We will now discuss the effect of increasing the alkyd content up to $25 \%$, keeping in mind that the hydrophobic character of the organic phase is significantly increased in the presence of alkyd. It should be noted that the trend of variation of $\mathrm{N}_{\mathrm{p}} / \mathrm{N}_{\mathrm{d}}$ in Figure 8 is similar to that of Figure 6 for a similar quantity of alkyd (e.g. 25\%), but with only one shot of initiator in Figure 8. Hence, it appears that homogeneous nucleation is independent of the intermittent addition of initiator. Recall that these are batch experiments, so the re-nucleation of particles observed for this second set of runs is not due to additional monomer or surfactant being added to the system, but rather to a change in the particle stability.

As noted above ( $c f$. Figure 2), the overall rate of polymerisation is lower with $25 \%$ alkyd than $5 \%$ alkyd, quite possibly due to the large droplets made at higher alkyd contents (the surface area of the $25 \%$ alkyd droplets is almost three times lower that that of the alkyd-free droplets). Nevertheless, if one compares Figure 4 (a-c), it can be seen that the rate of consumption of BA becomes relatively slower that than that of MMA, especially during the first 30 minutes of polymerisation. At $25 \%$ alkyds, when the overall monomer conversion is $45 \%$, the conversion of MMA is about $70 \%$ and the conversion of BA is about $20 \%$. In other words, the polymer formed in the first part of the experiment (i.e. before new particles are created by 
secondary nucleation) is rich in MMA. It has been shown in the literature that although MMA and an alkyd resin are totally miscible, alkyds and PMMA are incompatible ${ }^{26}$. In addition, a change in the particle morphology of alkyd-acrylic hybrids with monomer conversion leading to an acrylic rich shell and alkyd rich core has been observed ${ }^{24-26}$. It is therefore reasonable to assume that the morphology of the hybrid particles is changing to a PMMA rich shell and an alkyd/PBA rich core somewhere near 40-50\% overall monomer conversion at higher alkyd contents, and that this change will be all the more significant when the quantity of alkyd in the particle increases. This is coherent with the explanation for the limiting conversion provided above. Furthermore, as we will see in the latter part of this paper, the high alkyd content particles do not always form good films, and one can see the original particles remain more or less well defined in the final films. This implies that PMMA-rich polymer can be found on the outside of the particles.

This range of conversion corresponds to the point where one begins to see spontaneous renucleation of particles at higher alkyd contents in Figure 8. Apparently, for high alkyd contents, some monomer leaves the particles and is used to create a second, stable population of particles. Interestingly enough, the re-nucleation for the high alkyd content runs is nevertheless accompanied by a narrowing of the the polydispersity index (PI) obtained from the Nanosozer ( $c f$. Figure 7). The number of particles decreases during each of these runs (15 and $25 \%$ alkyd), meaning that the average particle size increases, but as the droplet size increases more than does the particle size, $\mathrm{Np} / \mathrm{Nd}$ increases. The monomer for the new particles needs a source, and given the evolution of the PSD, that source is most likely the larger particles (or even monomer droplets). It is worthwhile to mention that the particles formed by the homogenous nucleation cannot be hybrid particles. An undesirable outcome in these cases is greater heterogeneity across the particle population, which will translate into more heterogeneity in the final films.

As per the calculations shown in the Supporting Information, the area covered by one surfactant molecule, $A_{s}$, in the presence or absence of the alkyd is $100 \AA^{2} /$ molecule for our system, and therefore the surface coverage of droplets by the surfactant was always incomplete ( $c f$. Table 10). We can therefore conclude that there is not a significant release of surfactant in the system. It is therefore possible that the incompatibility between PMMA and alkyd could be a major reason for the increase of $\mathrm{N}_{\mathrm{p}} / \mathrm{N}_{\mathrm{d}}$. This incompatibility might cause the MMA be partially ejected from the particles during the second half of the reaction when the morphology of the particles changes. Note that since $A_{s}$ does not change when we add the alkyd resin, this further suggests that the droplets themselves are not entirely homogeneous. If the alkyd were located (even partially) at the interface of the droplets, one would expect to see $\mathrm{A}_{\mathrm{s}}$ decrease due to a drop in the polarity. The fact that this does not occur is evidence that the alkyd is essentially found near the centre of the droplets, surrounded by a "shell" of monomer.

\subsection{Attempts to reduce secondary nucleation}

These results led us to believe that it should therefore be possible to avoid secondary nucleation by controlling the nature of the organic phase. In an initial step, we removed ODA from our system in the presence of $25 \mathrm{wt} \%$ alkyd. As a result, the broad asymmetric droplet size distribution could be rearranged to a narrow symmetric distribution (Figure 10). 


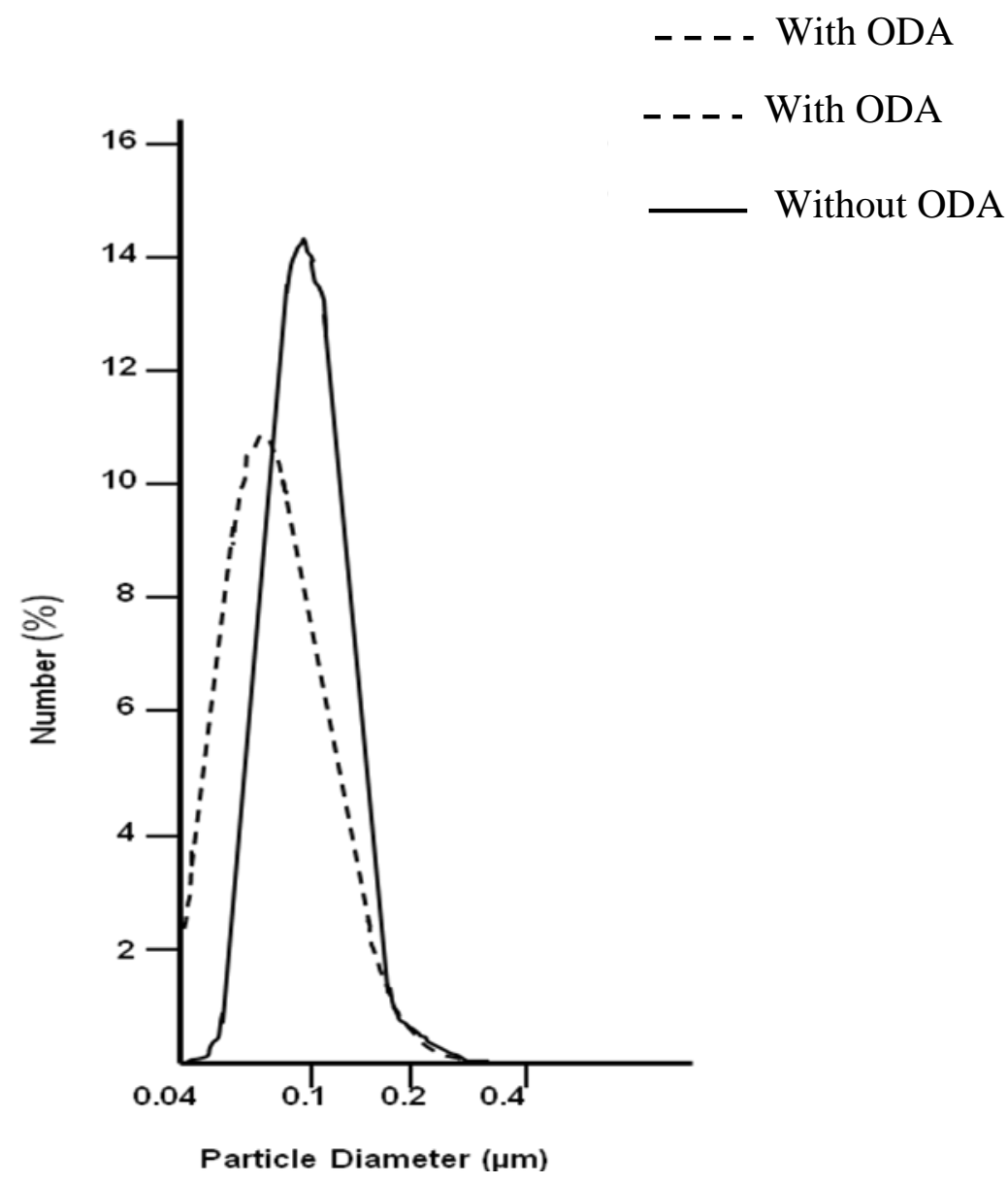

Figure 10. Droplet size distribution in the presence (---) and absence (-) of ODA for $50 \%$ monomer content MMA/BuA/AA miniemulsions containing $25 \mathrm{wt} \%$ alkyd

The evolution of $\mathrm{N}_{\mathrm{p}} / \mathrm{N}_{\mathrm{d}}$ for a new series of experiments with a total theoretical solid content of $50 \%$ by weight containing $25 \mathrm{wt} \%$ alkyd in the organic phase and having various monomer compositions in the absence of ODA (Runs 13-16 in Table 3) is shown in Figure 11. These experiments were compared to an experiment containing $25 \mathrm{wt} \%$ of the saturated alkyd resin (Run 16). 


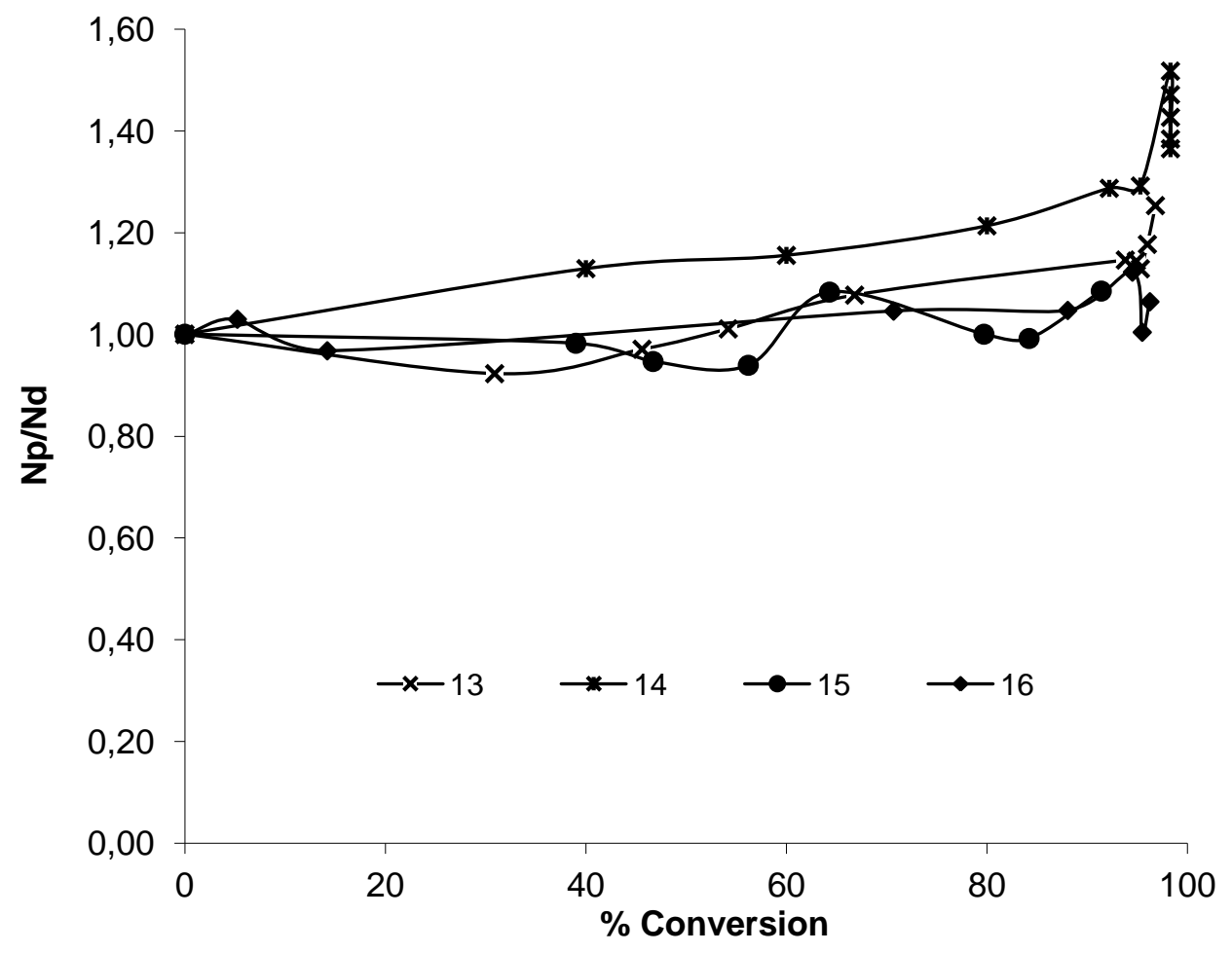

Figure 11. Variation of $\mathrm{N}_{\mathrm{p}} / \mathrm{N}_{\mathrm{d}}$ with conversion for miniemulsion polymerisation reactions performed according to the recipes of Table 10 in which ODA was removed and the composition of the monomer mixture was varied.

The degree of secondary nucleation late in the experiment is high when MMA is polymerized alone even in the absence of ODA (Run 14) - but still less than one notices in Figure 8 with $25 \%$ alkyds. This could be due to the very low grafting between PMMA and alkyd resulting in poor compatibility between both phases. However, the other experiments show relatively small changes in the $\mathrm{N}_{\mathrm{p}} / \mathrm{N}_{\mathrm{d}}$ ratio and a limiting conversion of approximately $96 \%$ as in the previous cases discussed above.

As we saw above, removing the ODA in the alkyd-containing formulations, the fraction of very small droplets created during miniemulsification is lower (Figure 10). This means that the overall surface area in the latex will be much lower, and as a result it is easier to stabilise the polymerising droplets. It appears that removing the ODA reduces the level of homogenous nucleation, and hence the $\mathrm{N}_{\mathrm{p}} / \mathrm{N}_{\mathrm{d}}$ ratio could be maintained closer to one.

\subsection{Film properties}

The objective of this series of experiments was to relate monomer conversion to film formation and morphology. The experimental recipes for this series of experiments are given in Table 4, while the characteristics of the miniemulsions and resulting latexes are shown in Table 11.

Table 11. Characteristics of the miniemulsions and latexes of experiments 17 to 23 (Table 4)

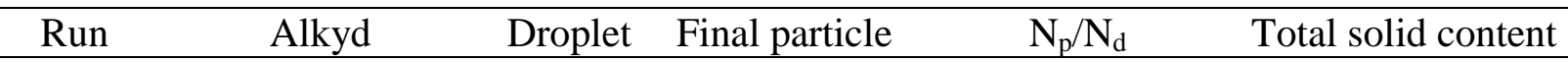




\begin{tabular}{cccccc}
\hline & $\begin{array}{c}\text { (wt\% by organic } \\
\text { phase) }\end{array}$ & $\begin{array}{c}\text { size } \\
(\mathrm{nm})\end{array}$ & size $(\mathrm{nm})$ & & (real) (wt\%) \\
\hline 17 & 0 & 113 & 120 & 0.8 & 45.0 \\
18 & 22 & 125 & 111 & 1.4 & 48.6 \\
20 & 22 & 117 & 112 & 1.1 & 46.5 \\
21 & 50 & 145 & 138 & 1.2 & 40.4 \\
22 & 50 & 144 & 139 & 1.1 & 44.0 \\
23 & 50 & 144 & 140 & 1.1 & 42.0 \\
\hline
\end{tabular}

Experiments were carried out to determine the influence of the type of initiator on the final film morphology. For comparison, the structure of an all-acrylic film (Run 17) was examined first. The AFM images in Figure 12 reveal that the particle identity has been retained. The particles have not coalesced at the film surface. DSC analysis has found the glass transition temperature $\left(\mathrm{T}_{\mathrm{g}}\right)$ of the latex to be $22{ }^{\circ} \mathrm{C}$. The film formation was carried out at only a slightly higher temperature $\left(23^{\circ} \mathrm{C}\right)$. The polymer viscosity will be exceedingly high during film formation, and a model of the process predicts slow particle deformation by a dry sintering mechanism ${ }^{35}$. As we mentioned above, the fact that the particles retain their identity under film forming conditions supports the notion that the particle structure evolves toward a core-shell-like morphology with a high $\mathrm{T}_{\mathrm{g}}$, PMMA-rich shell, and as a result a much softer core with a PBA-rich copolymer. 

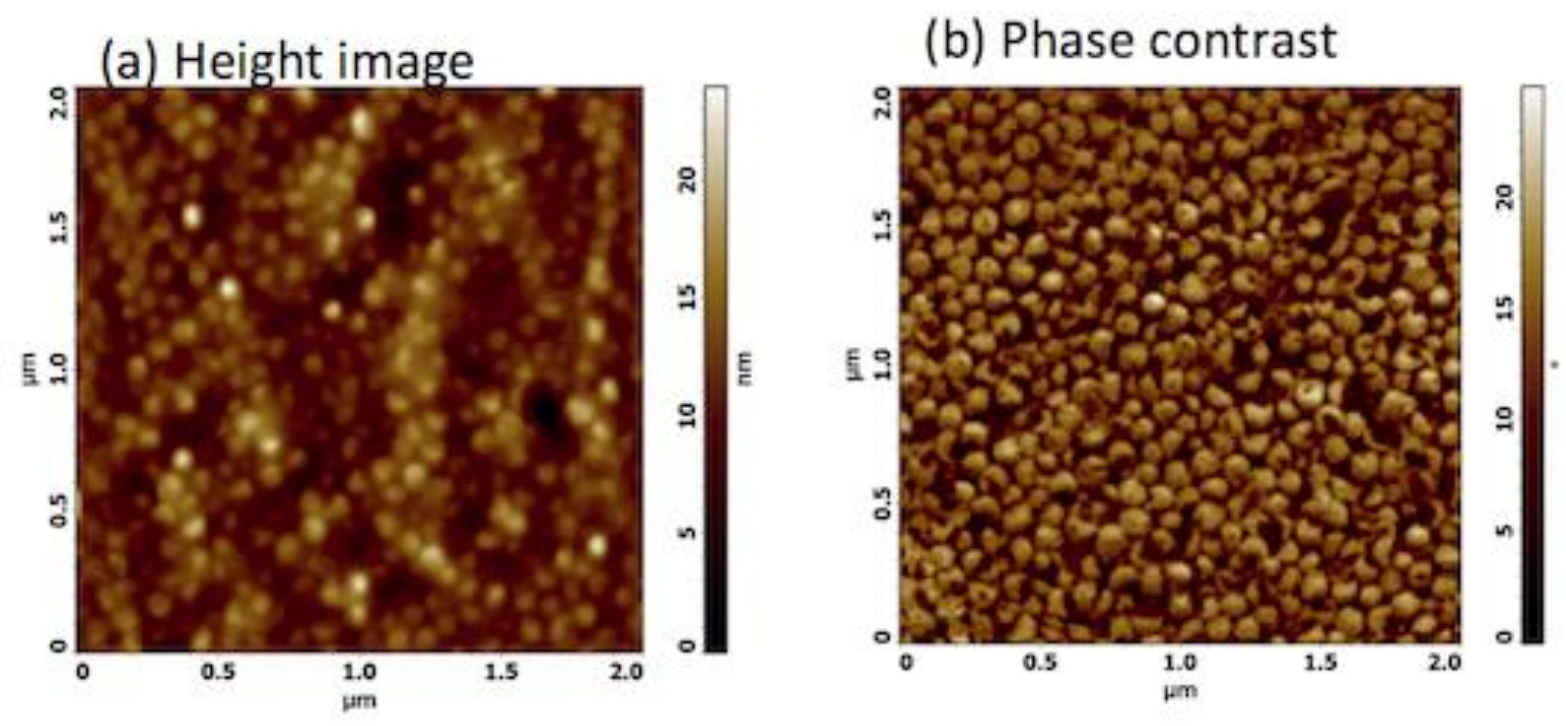

(c) Magnification of (b)

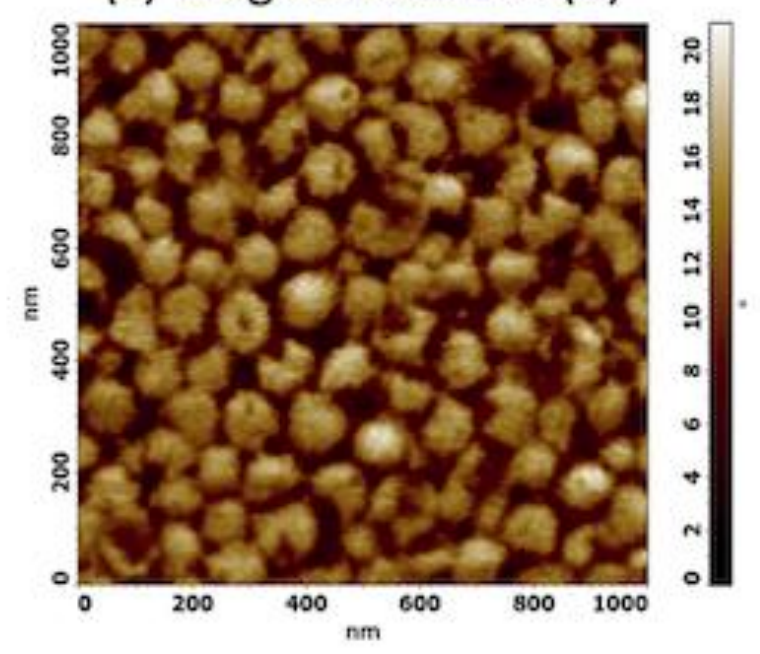

Figure 12. AFM images of the surface of an all-acrylic latex (Run 17 in Table 4) film: (a) height image and (b) phase contrast image. The scan area is $2 \mu \mathrm{m} \times 2 \mu \mathrm{m}$. (c) A phase contrast image of the same surface at a higher magnification. The scan area is $1 \mu \mathrm{m} \times 1 \mu \mathrm{m}$.

The structure of the film in Figure 12 can be compared with the structure obtained when the alkyd resin was introduced into the polymer matrix (Run 23). The nanostructure of the hybrid film, as shown in Figure 13, differs markedly. Particle identity is not distinct, which indicates that particle coalescence has occurred. An explanation is obtained from thermal analysis. Two $T_{\mathrm{g}}$ were found in DSC analysis of the hybrid: a higher one at $19{ }^{\circ} \mathrm{C}$, and a lower one at $20{ }^{\circ} \mathrm{C}$. The existence of two transitions indicates the existence of two phases. The upper transition is ascribed to the acrylic after plasticization by the alkyd, to reduce its $T_{\mathrm{g}}$ by 3 degrees. The plasticized acrylic particles will deform at a greater rate than the neat acrylic. The lower transition is ascribed to an alkyd-rich phase; analysis of the neat alkyd found a $T_{\mathrm{g}}$ of $-43^{\circ} \mathrm{C}$.

Upon close examination of Figure 13, some contrast can be seen in both the height and phase images, in regions that are only tens of $\mathrm{nm}$ in size. This size scale is smaller than the particle size. Hence, a likely explanation is that there is heterogeneity within the particles. The alkyd 
is a viscous liquid that is expected to lead to greater energy dissipation during AFM imaging in comparison to the acrylic copolymer. The dark spots in the phase image are therefore attributed to alkyd-rich regions within the particles. AFM can be sensitive to subsurface structures, so the alkyd phase could be encapsulated within the particles but still be apparent in the images. In the topographic images, the alkyd regions could appear darker because of greater indentation of the AFM tip in the softer phase ${ }^{36}$.
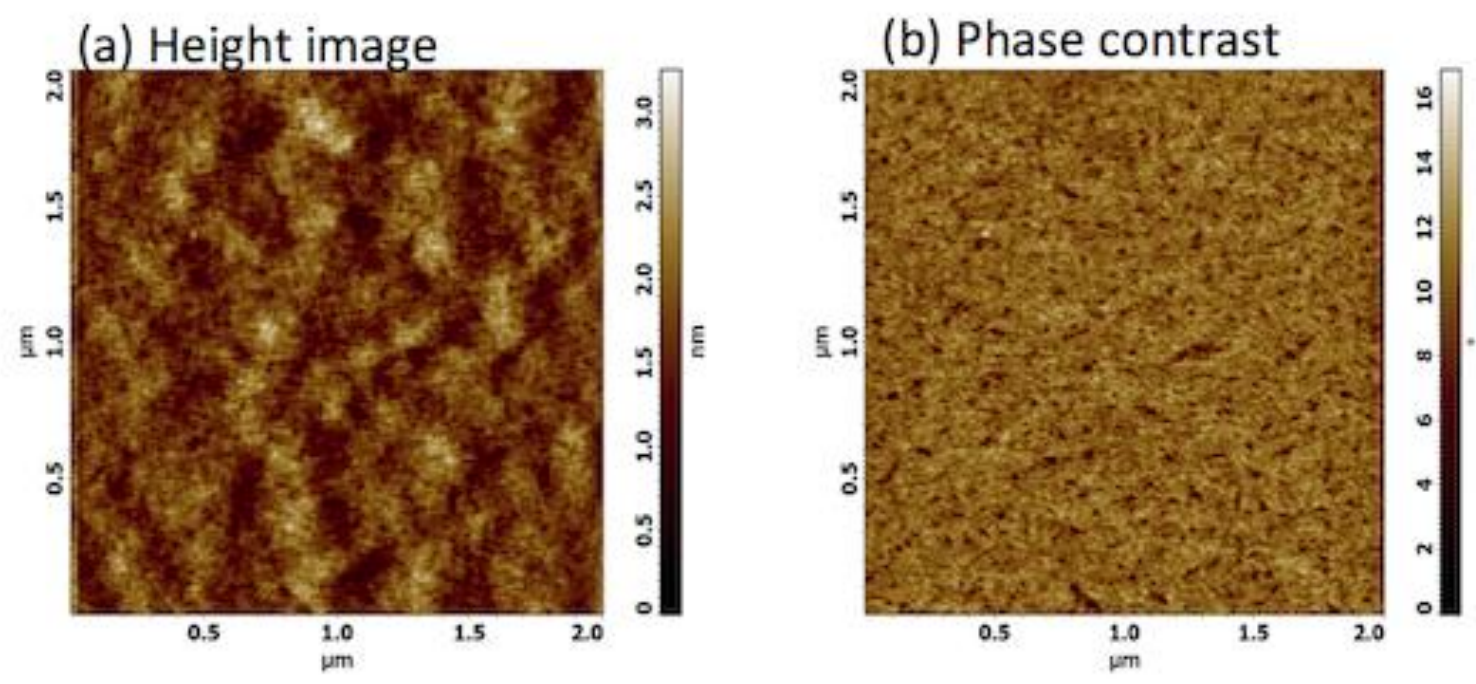

Figure 13. AFM images of the surface of a film cast from the hybrid latex with KPS as the initiator (Run 23 in Table 4): (a) height image and (b) phase-contrast image. Scan area is 2 $\mu \mathrm{m} \times 2 \mu \mathrm{m}$.

The choice of initiator was found to have a pronounced effect on the film structure. When AIBN was used instead of KPS (Run 22), the film morphology is much different than what was found when KPS was used (Run 23). Figure 14(a) and (b) show that in the AFM images of run 22, two phases can be clearly seen. The dark regions in the phase image are attributed to an alkyd-rich composition. The regions are up to $1 \mu \mathrm{m}$ across in some areas, which is much greater than the particle size. Hence, it appears that phase separation between the alkyd and acrylic phases has occurred. Thermal analysis is in agreement, as it reveals two glass transitions. 
(a) Height image

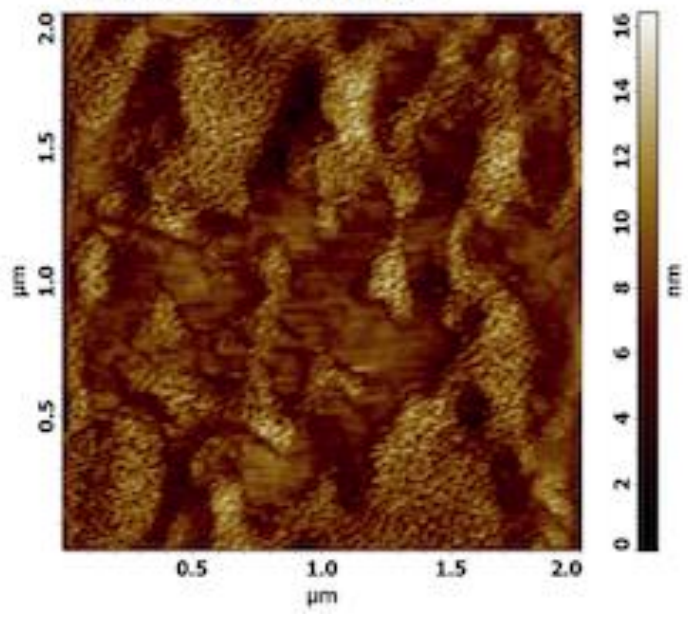

(b) Phase contrast

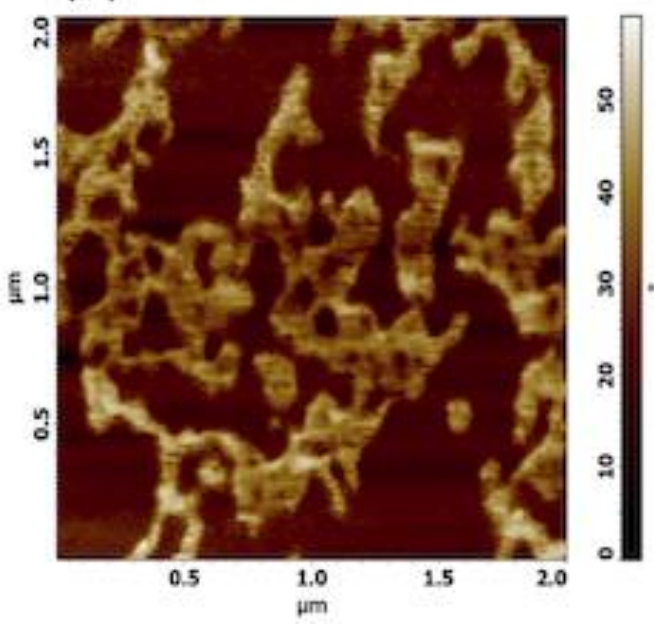

Figure 14. AFM images of the surface of a films cast from a hybrid latex with AIBN as the initiator (Run 22): (a) height image and (b) phase-contrast image. Scan area is $2 \mu \mathrm{m} \times 2 \mu \mathrm{m}$.

The question now arises as to why there is such a pronounced effect of the initiator on the final film morphology. While the answer is not immediately obvious, it is clear that the alkyd phase (darker) and acrylic polymers are really quite separated. If we consider the two particle morphologies, we might hypothesize that the KPS initiated particles will have some portion of ionic charge on the acrylic polymer interface with water leading to a lower interfacial tension than the AIBN case which would not offer any charge based lowering of the acrylic interfacial tension. It may be that the equilibrium preferred morphology for the KPS case would be a core/shell while the AIBN case more likely a hemisphere. The hemisphere morphology, coupled with lower grafting in the AIBN case, then would certainly more easily phase separate during and after film formation.

The structure of a film made from a latex initiated with KPS and containing $22 \mathrm{wt} \%$ alkyd (Run 18) is presented in Figure 15. The film structure can be considered to be intermediate between what was found for the acrylate homopolymer ( $c f$. Figure 12) and the hybrid with 50 wt\% alkyd ( $c f$. Figure 13). There are brighter regions with a diameter on the order of $100 \mathrm{~nm}$, which are likely to be acrylate-rich particles. There is some particle identity retained in the film, because there is less plasticization with $22 \mathrm{wt} \%$ alkyd in comparison to what was found for $50 \mathrm{wt} \%$ alkyd hybrids. With KPS as the initiator, the amount of phase separation at the film surface is less than what is found when AIBN was used ( $c f$. Figure 14). 
(a) Height image

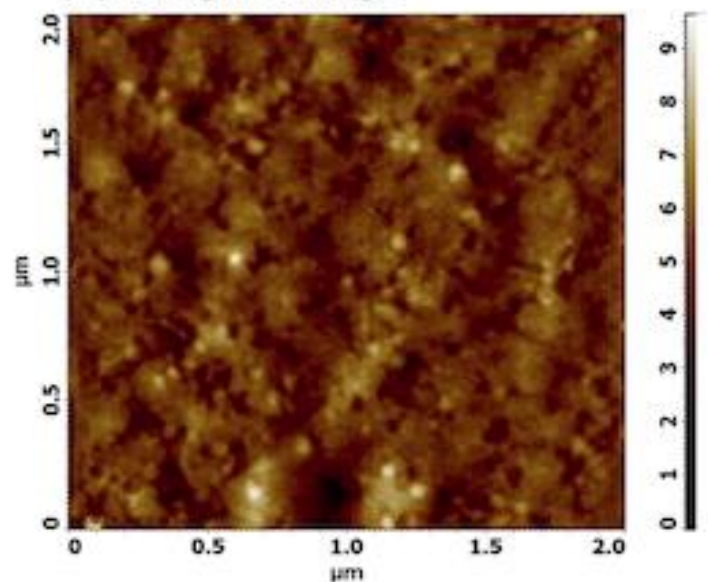

(b) Phase contrast

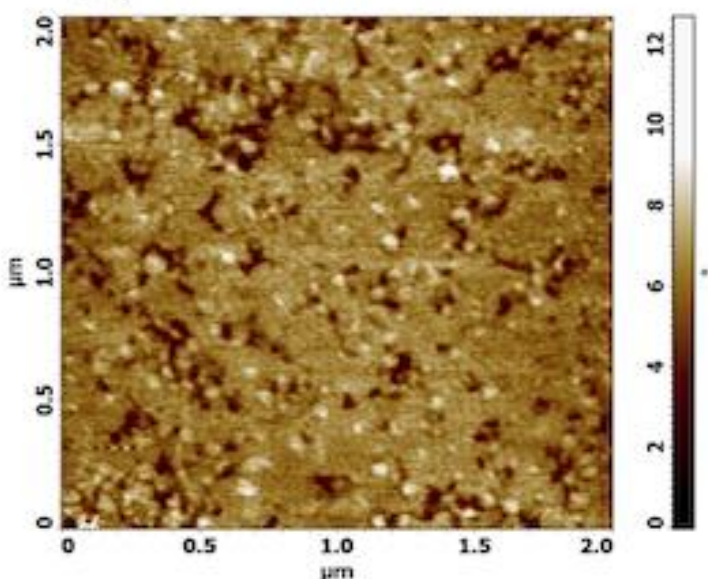

Figure 15. AFM images of the surface of a film cast from a hybrid latex with KPS as the initiator and containing $22 \mathrm{wt} \%$ alkyd (Run 18 in Table 4): (a) height and (b) phase. Scan area is $2 \mu \mathrm{m} \times 2 \mu \mathrm{m}$.

\section{Conclusions}

Stable miniemulsions and complete monomer conversions could be achieved while maintaining the ratio of initial number of droplets to final number of particles between 0.8 and 1 when the alkyd quantity was $5 \%$ or less. However with the gradual increase of alkyd quantity, the final monomer conversion gradually decreased. Regardless of the strategy used, complete monomer conversion could not be achieved even by adding extra shots of initiator late in the process, and the overall conversion could not be brought higher than $96 \%$ (for a hybrid system of $25 \%$ alkyd and $50 \%$ solids), and even then it was found to be necessary to purify the alkyd. A study of the individual conversions of the two main monomers, MMA and BA, shows that the limiting conversion is specifically related to BA with this particular alkyd (Nuplex Setal 293-XX). As the alkyd content rises, the rate of polymerisation of BA drops with respect to that of MMA. Similar behaviour for the saturated alkyd case suggests that it is not the degree of grafting, but rather internal phase separation of the acrylic copolymer and alkyd in the particle, combined with a partitioning of the butyl acrylate monomer between both phases that accounts for the limiting conversion.

The evolution of the ratio of the number of particles to the number of original droplets, $\mathrm{N}_{\mathrm{p}} / \mathrm{N}_{\mathrm{d}}$ as a function of monomer conversion shows that the observed increase of $\mathrm{N}_{\mathrm{p}} / \mathrm{N}_{\mathrm{d}}$ after about $40 \%$ monomer conversion in the presence of high alkyd quantity $(15-25 \%)$ is independent of the initiator system but dependent on the hydrophobicity. In the standard recipes, the increase in this ratio appears to coincide with almost complete MMA conversion (and relatively low BA conversion). This result suggests that the particles phase separate during the reaction, and that poor control of the formation of secondary particles coincides with this phase separation. Removing the ODA as a hydrophobe from the recipe (essentially depending on the alkyd to play this role) allowed us to maintain $\mathrm{N}_{\mathrm{p}} / \mathrm{N}_{\mathrm{d}}$ at 1.2, even for high alkyd contents. This tells us that one can limit the secondary nucleation, but not eliminate it. More importantly it also suggests that changing the composition of the particles (degree of hydrophobicity) will change the stability of the system.

Finally, it was shown that the polymer morphology can be affected for these hybrids by the initiator choice. The most homogeneous film morphology was obtained from a latex with $44 \%$ solids, a composition of $50 \mathrm{wt} \%$ alkyd, and KPS as the initiator. When AIBN was used 
in the recipe instead of KPS, the film showed a clear phase separation for a similar monomer and surfactant formulation.

\section{Acknowledgment}

Funding was provided by the European Commission's Sixth Framework Programme through the NAPOLEON Project (Contract number IP 011844-2). We thank Mrs. V. Doukova and Mr. A. Utgenannt (University of Surrey) for assistance with the DSC analysis.

\section{Supporting Information Available}

Experimental procedure to determine the percentage coverage of latex by surfactant and $\mathrm{A}_{\mathrm{s}}$ of the surfactant. Recipes of the miniemulsion polymerisation reactions carried out with the aim to increase monomer conversion. The dependence of droplet size on dispersed phase viscosity. ${ }^{1} \mathrm{H}$ and ${ }^{13} \mathrm{C}$ NMR spectra of pure alkyd resin and alkyd-grafted copolymer containing $25 \%$ alkyd. This material is available free of charge.

\section{References}

1. Hamersveld, E. M. S. V.; Van Es, J. J. G. S.; Cuperus, F. P. Colloids and Surfaces A: Physiochemical and Engineering Aspects 1999, 153, 285-296.

2. Shoaf, G. L.; Stockl, R. R. Polymer Reaction Engineering 2003, 11, 319-334.

3. Hofland, A., Prog. Org. Coat., 2012, 73, 274-282

4. Schork, F. J.; Tsavalas, J. G. Progr Colloid Polym Sci 2004, 124, 126-130.

5. Tsavalas, J. G.; Luo, Y.; Schork, F. J. Journal of Applied Polymer Science 2003, 87, $1825-1836$

6. Wu, X. Q.; Schork, F. J.; Gooch, J. W. Journal of Polymer Science: Part A: Polymer Chemistry 1999, 37, 4159.

7. Guyot, A.; Landfester, K.; Schork, F.J.: Wang, C.; Prog. Polym. Sci., 2007, 32, 14391461.

8. Landfester, K. Angewandte Chemie International Edition 2009, 48:4488-4507

9. Schork, F. J.; Poehlein, G. W.; Wang, S.; Reimers, J.; Rodrigues, J.; Samer, C. Colloids and Surfaces A: Physiochemical and Engineering Aspects 1999, 153, 39-45.

10. Antonietti, M.; Landfester, K. Prog.Polym.Sci 2002, 27, 689-757.

11. Asua, J. M. Prog.Polym.Sci 2002, 27, 1283-1346.

12. Sood, A.; Awasthi, S. K. Journal of Applied Polymer Science 2003, 88, 3058-3065.

13. Minari, R.J.; Goikoetxea, M.; Beristain, I.; Paulis, M.; Barandiaran, M.J.; Asua, J.M., Polymer 2009, 50, 5892-5900. 
14. Goikoetxea, M.; Minari, R.J.; Beristain, I.; Paulis, M.; Barandiaran, M.J.; Asua, J.M.,, J Poly Sci Part A Pol Chem 2009, 47, 4871-4885.

15. Goikoetxea, M.; Minari, R.J.; Beristain, I.; Paulis, M.; Barandiaran, M.J.; Asua, J.M., Polymer 2010, 51, 5313-5317.

16. Goikoetxea, M.; Reyes, Y.; de las Heras Alarcón, C.M.; Minari, R.J.; Beristain, I.; Paulis, M.; Barandiaran, M.J.; Keddie, J.L.; Asua, J.M., Polymer 2012, 53, 1098-1108.

17. Dziczkowski, J.; Dudipala, V.; Soucek, M.D., Progress in Organic Coatings 2012, 73, 294-307.

18. Dziczkowski, J.; Dudipala, V.; Soucek, M.D., Progress in Organic Coatings 2012, 73, 308-320.

19. Wang, T.; de las Heras Alarcón, C.M.; Goikoetxea, M.; Beristain, I.; Paulis, M.;

Barandiaran, M.J.; Asua, J.M.; Keddie, J.L., Langmuir 2010, 26(17), 14323-14333.

20. Heiskanen, N.; Jämsä, S.; Paajanen, L.; Koskimies, S., Progress in Organic Coatings 2010, 67, 329-338.

21. Rämänen, P.; Maunu, S.L., Progress in Organic Coatings 2014, 77, 361-368.

22. Elrebii, M.; Mabrouk, A.B.; Boufi, S., Progress in Organic Coatings 2014, 77, 757-764.

23. E. Degrandi-Contraires, E.; Udagama, R.; Creton, C.; McKenna, T.F.L., Bourgeat-Lami, E.; Plummer, C.; Int. J. Adhesion Adhesives, 2014, 50, 176-182

24. Tsavalas, J. G.; Luo, Y.; Hudda, L.; Schork, F. J. Polymer Reaction Engineering 2003, 11 277-304.

25. Hudda, L.; Tsavalas, J. G.; Schork, F. J. Polymer 2005, 46, 993-1001.

26. Tsavalas, J. G.; Schork, F. J.; Landfester, K. JCT Research 2004, 1, 53-63.

27. Deriss, M. J.; Karlsson, O. J. Surface Coatings International Part B: Coatings Transactions 2005, 88, 231-316.

28. Colombini, D.; Derris, M. J.; Karlsson, O. J.; Maurer, F. H. J. Macromolecules 2004, 37, 2596-2602.

29. Derris, M. J.; Karlsson, O. J. Progr Colloid Polym Sci 2004 124, 149-153.

30. Guo, J.; Schork, F.J. Macromol. React. Eng. 2008, 2, 265-276.

31. Mallégol, J.; Dupont, O.; Keddie, J.L. Langmuir 2001, 17, 7022-31.

32. McKenna, T. F.; Villanueva, A.; Santos, A. M. J. Polym. Sci., Part A: Polym. Chem 1999, 37, (5), 571-588. 
33. McKenna, T. F.; Villanueva, A. J. Polym. Sci., Part A: Polym. Chem. 1999, 37, (5), 589601.

34. Nikitin, A. N.; Hutchinson, R. A. Macromolecules 2005, 38, 1581-1590.

35. Routh, A.F.; Russel, W.B. Industrial \& Engineering Chemistry Research 2001, 40, 43024308.

36. Lei, C.; Ouzineb, K.; Dupont, O.; Keddie, J.L. J. Coll. Interf. Sci. 2007, 307, 56-63. 
Table of Contents Graphic

Acrylic-Alkyd Hybrids: Secondary Nucleation, Particle Morphology and Limiting Conversions

Ravindra Udagama, Carolina de las Heras Alarcón, Joseph L. Keddie, John G. Tsavalas, Elodie Bourgeat-Lami, Timothy F.L. McKenna

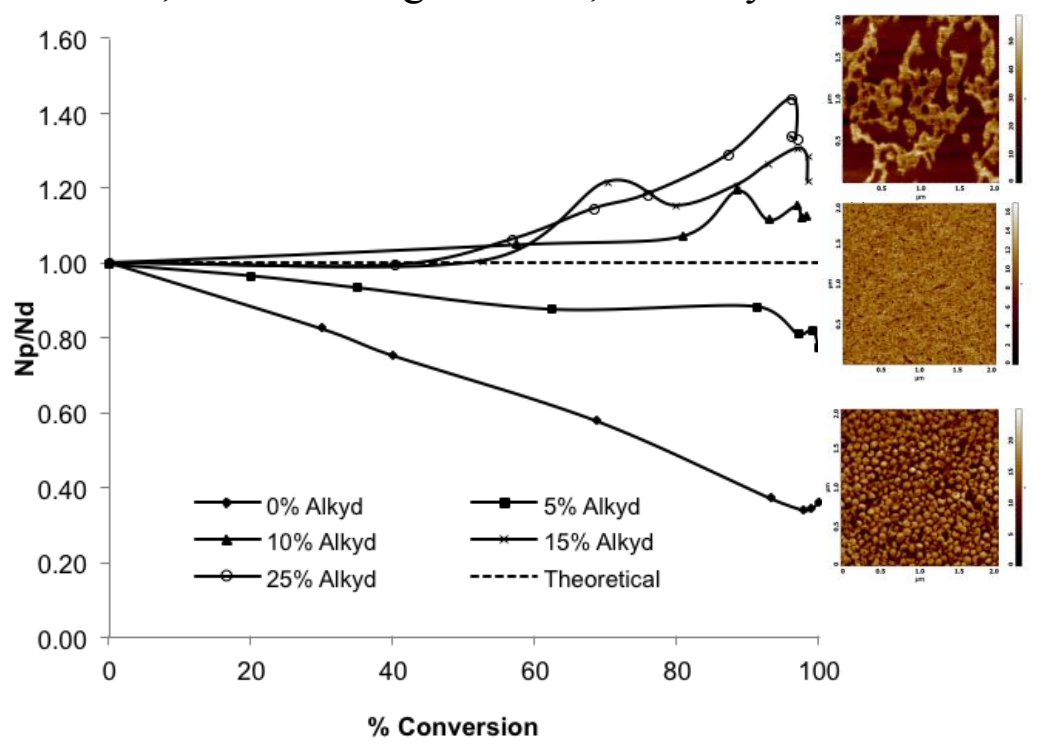

Ratio of particle to droplet number and phase contrast AFM images of the surface of a films cast from hybrid latexes 